\title{
IDAHO NATIONAL LABORATORY QUARTERLY PERFORMANCE ANALYSIS - 1ST QUARTER FY2015
}

Lisbeth A. Mitchell

February 2015

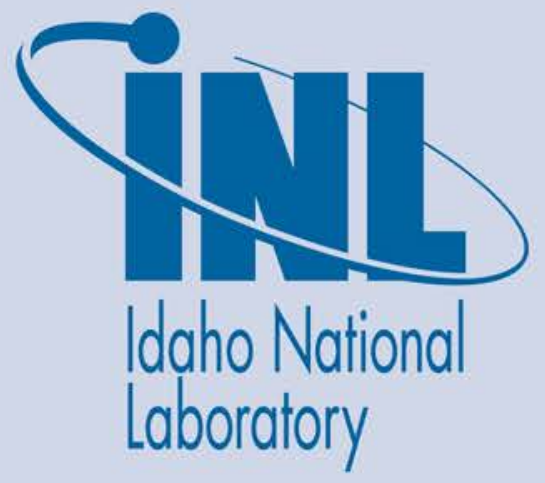

The INL is a U.S. Department of Energy National Laboratory operated by Battelle Energy Alliance 
INL/EXT-15-34291

\section{IDAHO NATIONAL LABORATORY QUARTERLY PERFORMANCE ANALYSIS - 1ST QUARTER FY2015}

Lisbeth A. Mitchell

February 2015

Idaho National Laboratory

Idaho Falls, Idaho 83415

http://www.inl.gov

Prepared for the

U.S. Department of Energy

Office of Nuclear Energy

Under DOE Idaho Operations Office

Contract DE-AC07-05ID14517 


\section{IDAHO NATIONAL}

\section{LABORATORY}

\section{QUARTERLY PERFORMANCE ANALYSIS}




\section{Contents}

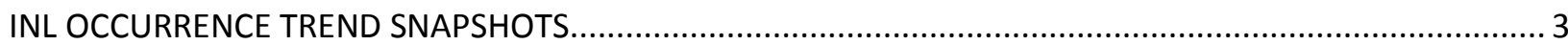

KEY LESSONS LEARNED ISSUED BY INL ORGANIZATIONS ................................................... 4

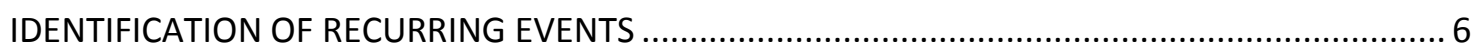

ANALYSIS OF PERFORMANCE COMPARED TO OTHER COMPLEX REPORTING .......................... 7

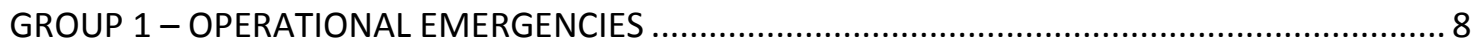

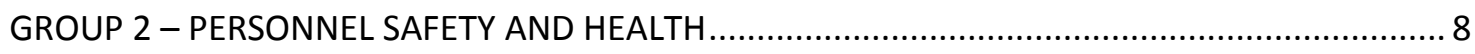

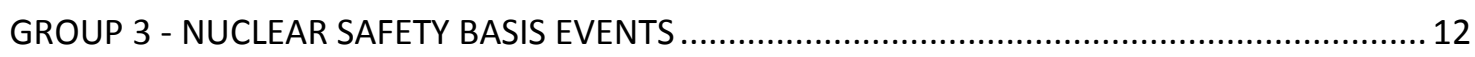

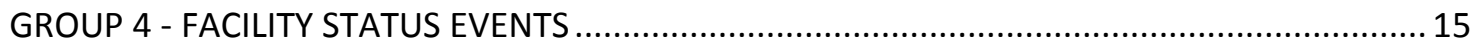

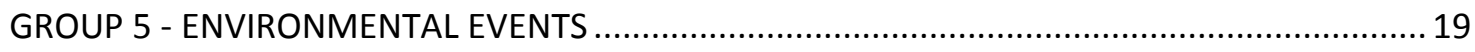

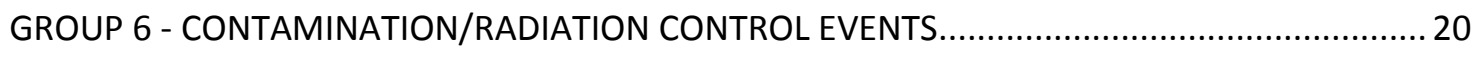

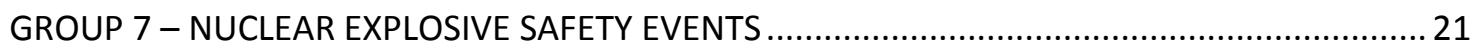

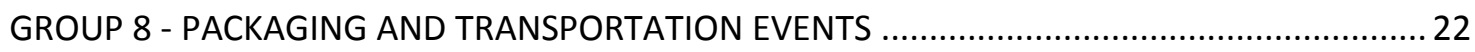

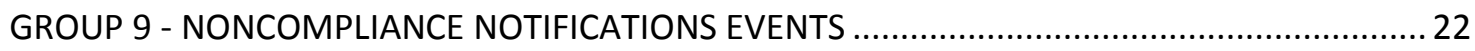

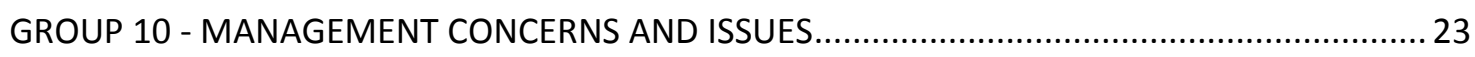

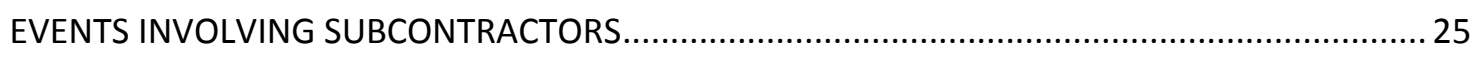

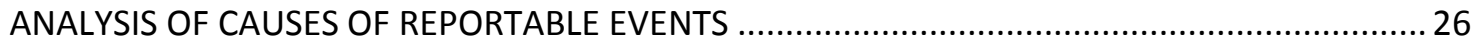

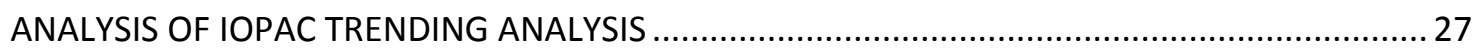


INL/EXT-15-34291

FY-15 15t Quarter

This report is published quarterly by the Idaho National Laboratory (INL) Quality and Performance Management Organization.

The Department of Energy (DOE) Occurrence Reporting and Processing System (ORPS), as prescribed in DOE Order 232.2,

"Occurrence Reporting and Processing of Operations

Information," requires a quarterly analysis of events, both reportable and not reportable, for the previous 12 months.

This report is the analysis of 73 reportable events (27 from the $1^{\text {St }}$ Qtr FY-15 and 46 from the prior three reporting quarters), as well as 38 other issue reports (including nine not reportable events and Significant Category A and $B$ conditions reported during the1st Qtr FY-15) identified at INL during the past 12 months.

Battelle Energy Alliance (BEA) operates the INL under contract

DE-AC07-051D14517.
Highlights...

The average number of events at the INL each quarter increased from 20 in FY-13 and 15 in FY-14 to 27 the first quarter of FY15. Thirty three percent of these were associated with performance degradation of safety class safety significant components at the Advanced Test Reactor (ATR).

The rate of significant events (those reported as Operational Emergencies, Recurring Issues, and/or Significance Categories 1 or 2) is trending downward over the past 24 months.

Over the past 24 months, the average number of days between significant occurrences is increasing, indicating that significant events are occurring less frequently. An increase in the number of days between significant events is a positive trend.

This quarterly analysis reviews those events that were reportable through ORPS, events that did not meet ORPS reporting thresholds, some conditions tracked in LabWay, the causes of reportable events, and trending performed by the INL Operational

Performance Analysis Committee (IOPAC) group.

The report also provides a summary of the more significant Lessons Learned issued by INL.
Occurrence Reporting Rates through the 1st Qtr FY15

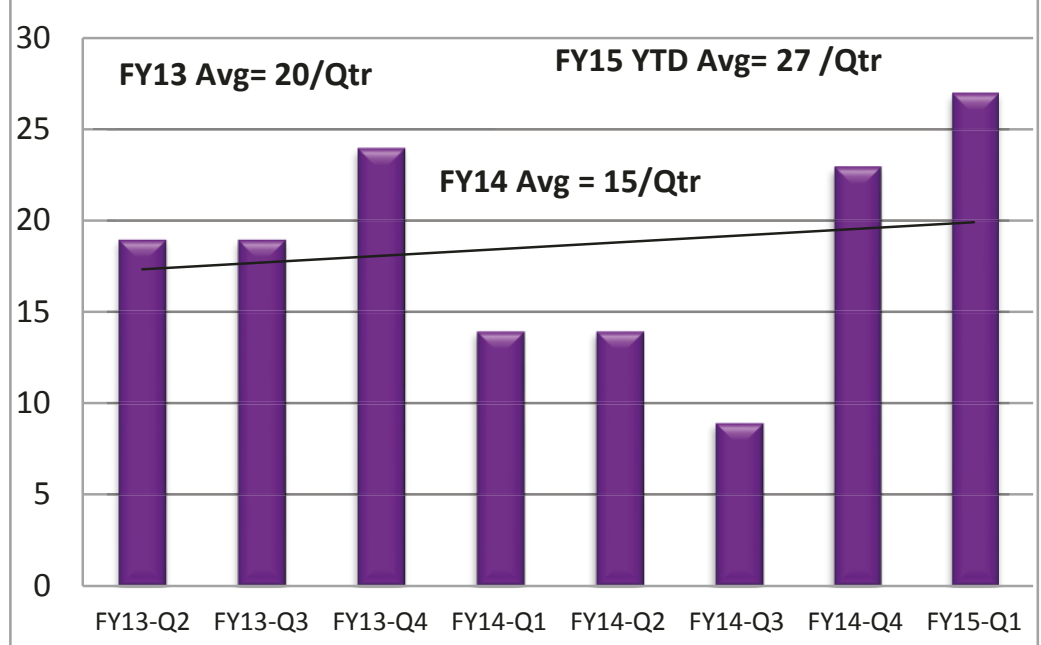

\section{Significant Occurrences Reported (Category OE, R, 1, and 2)}

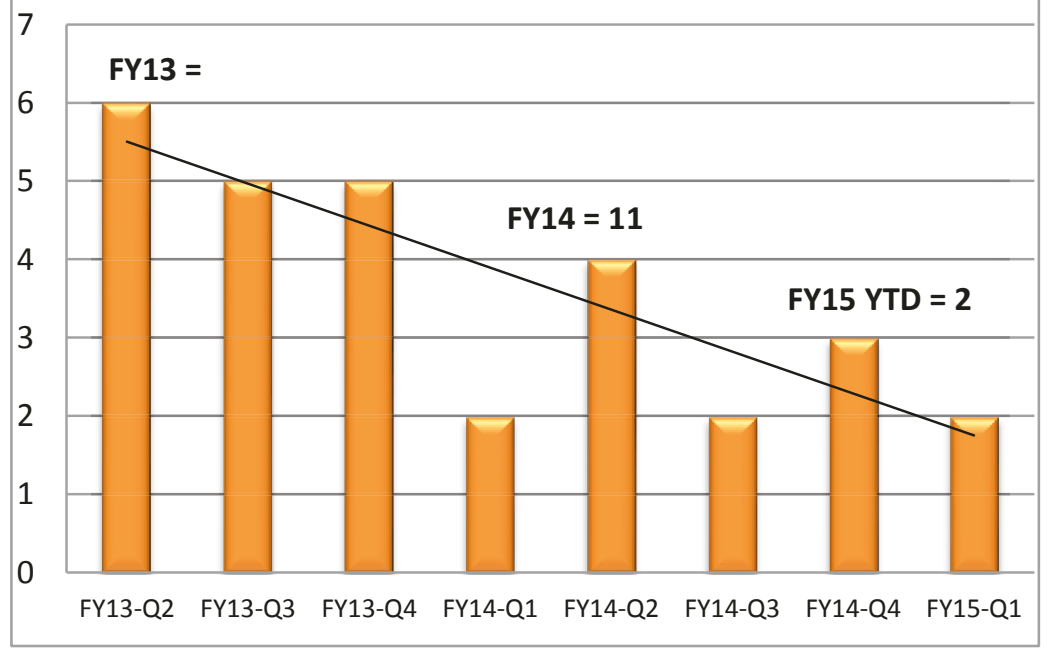

Average Days Between Significant Occurrences (Category OE, R, 1, and 2)

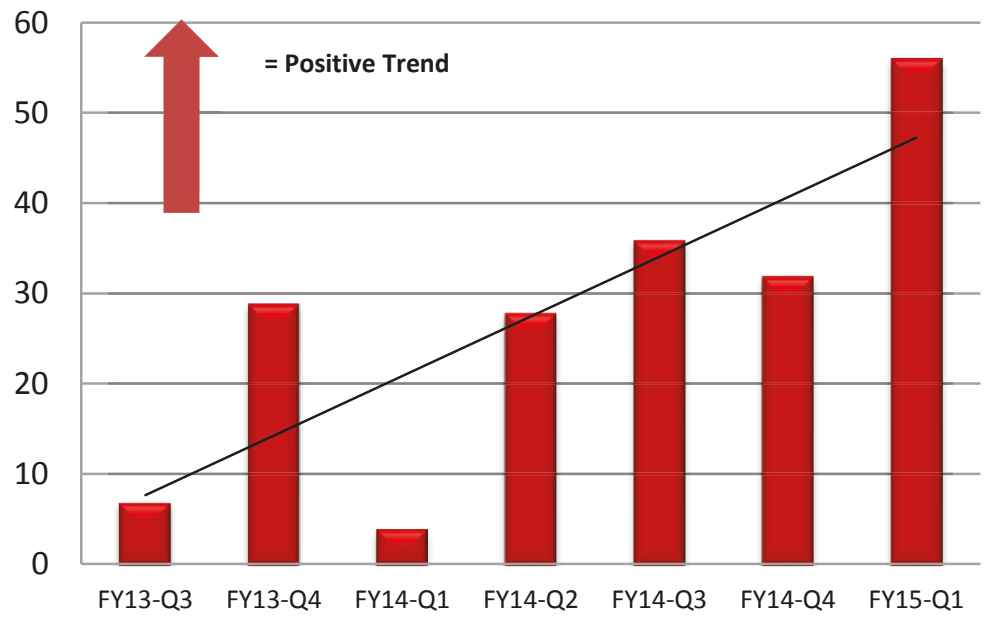




\section{INL Occurrence Trend Snapshots}

From 10/01/2014 through 12/31/2014, INL reported 27 new events to DOE, in accordance with DOE Order 232.2. These events were analyzed to determine commonalities related to: Operational Emergencies (Group 1), Personnel Safety and Health (Group 2), Nuclear Safety Basis (Group 3), Facility Status (Group 4), Environmental (Group 5), Contamination and Radiation Control (Group 6), Nuclear Explosive Safety (Group 7), Packaging and Transportation (Group 8), Noncompliance Notifications (Group 9), and Management Concerns (Group 10).

In addition, INL reported 16 events and conditions through Initial Notification Reports (INRs) and INL's local issues tracking software (LabWay) that did not meet ORPS reporting thresholds. There was no additional Significance Category A or B conditions reported in LabWay that were not already ORPS reportable.

\section{TREND SNAPSHOT}

\section{Occurrences by Facility: During the} reporting quarter, the Advanced Test Reactor (ATR), Central Facilities Area (CFA), and the Materials and Fuels Complex (MFC) experienced an increase in the number of events reported. ATR reported $52 \%$ of the events during this reporting quarter and MFC $26 \%$. Analysis of the nature and causes of all the reportable events is covered in additional sections of this report.

Additionally, the number of INRs submitted during the reporting period increased from 24 last quarter to 34 this quarter.
Occurrence Reports by Facility

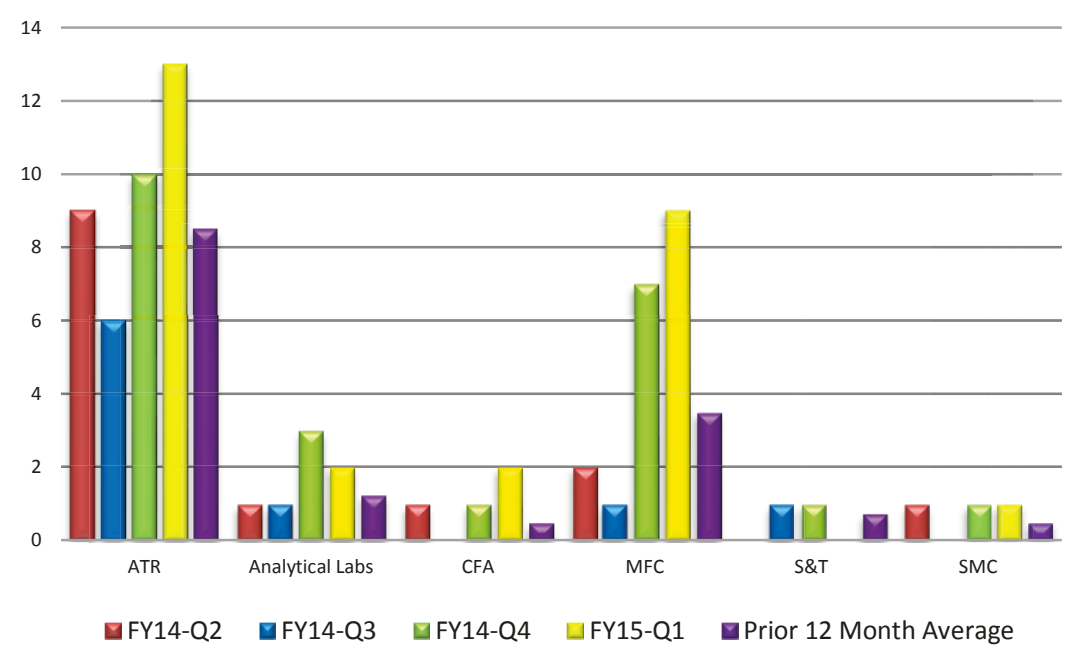

Occurrence by Reporting Criteria

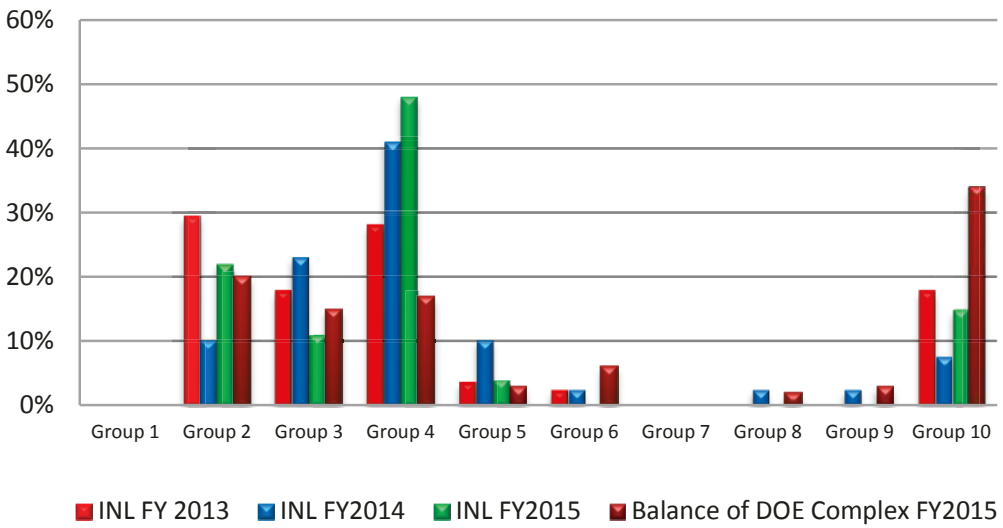

\section{TREND SNAPSHOT}

\section{Occurrences by Reporting Criteria:}

During FY-15, INL has experienced the majority of events related to: Group 4, Facility Status (48\%), Group 2, Personnel Safety and Health (22\%), Group 3, Nuclear Safety Basis (11\%), and Groups 10 Management Concerns (15\%). Comparative analysis to the balance of the DOE complex is shown in the chart to the right and is explained in each section of the report that follows. 


\section{SNAPSHOT}

Lessons Learned Events: During the $1^{\text {st }}$ Qtr FY-15, the use of Lessons Learned showed increased improvement. In December 2014, INL implemented OPEXShare, a new tool that offers a significantly enhanced source of high-quality, relevant lessons learned in an intuitive, user-friendly format. Lessons Learned coordinators and performance analysts within each mission center were trained to support the new tool.

The INL Lessons Learned Program is an integral part of the feedback and improvement processes required by DOE. Operational excellence requires the use of internal and external operating experience information (OEI) to minimize the likelihood of undesirable behaviors and promote noteworthy practices. Lessons learned are systematically evaluated and implemented to continuously improve performance. INL embraces the philosophy that Lessons Learned are lessons applied.

During the $1^{\text {st }}$ Qtr FY-15, INL used internally generated and/or lessons shared from other sites to improve operations and learn from other's events or mistakes. Of this data, four lessons, two of which were internally generated, were entered into the INL database to be shared across the INL prior to migration to OPEXShare. Following INL's transition to OPEXShare, all lessons and operating experience generated across the complex are now made available to INL personnel. Furthermore, INL will be better able to share internal lessons. The four lessons shared by INL are summarized below:

\section{Discharge Port Cap Failure on a Pressurized Manifold} Lesson 2014-1726 (Blue -Information) On 10/17/14, Fire Department personnel were involved in completing monthly operational checks on Wildland Unit \#4 truck at the CFA fire station. The checks involved flowing water from a manifold system located on the North side of the fire station.

The manifold consists of three $2 \frac{1 / 2}{2}$ discharge ports controlled by a single butterfly valve. Unit \#4 was parked adjacent to the manifold and a fire hose was attached to one of the ports. The other two remaining ports were capped. A firefighter verified that the caps on the two remaining ports were tight prior to beginning the operational check. The butterfly valve was then operated, allowing water to flow through the manifold. The resulting flow (up to 150 psi) caused a undetected damaged manifold discharge cap to be forcibly ejected. The cap struck the pump operators panel on the wildland unit. A second firefighter was standing near the panel as it was struck. No injury occurred to either firefighter and no noticeable damage occurred to the vehicle.

The manifold system was closed via the butterfly valve and the incident was reported to the Company Officer and Battalion Chiefs on duty.

The lesson we can take away from this event is that performing a thorough inspection of equipment prior to use is essential in preventing potential injury to personnel and/or damage to equipment. Any port caps used in similar manifold systems should be thoroughly inspected prior to use to ensure that the caps are in good condition. Failure to do so can result in the caps being displaced when pressure is applied to the system.

\section{Losing Control: Material Handling Dangers}

Lesson 2014-1724 (Blue - Information)

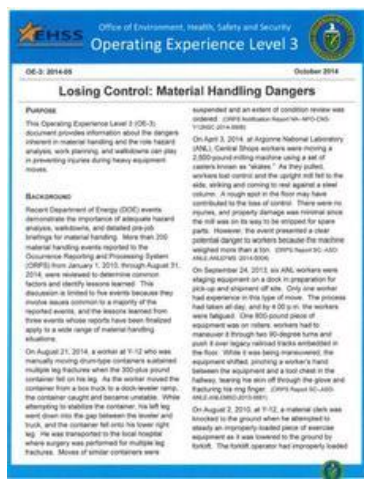
The DOE Office of Environment, Health, Safety and Security issue an Operating Experience Level 3 report to provide information about the dangers inherent in material handling and the role hazard analysis, work planning, and walkdowns can play in preventing injuries during heavy equipment moves. The document provides recent event summaries, associated corrective actions, and recommendations regarding work planning and hazard analysis that must be conducted to ensure safe material moves. 
The five events analyzed in the report were reviewed to determine common factors, lessons learned, and areas for improvement. The analysis found that all of the events would have benefited from more careful work planning and hazard analysis, including walkdowns to discovery obstacles and "what if" aspects.

The events highlighted in the report demonstrate that work planning for material moves must include walkdowns of the area(s), review of collateral tasks that may affect work completion and result in worker fatigue, and possible reevaluation of the work categorized as "skill of the craft." Additional hazard analysis may be necessary to ensure that material moves can be completed safely.

\section{First Alert - Inadequate Controls Near Hazardous Energy}

Lesson 2014-1725 (Yellow - Caution)

On 10/9/14, roof repair work was being performed on the south portion of the $\mathrm{H}$-Canyon truckwell airlock at the Savannah River Site (SRS). During the work evolution, it was discovered that the required controls were not in place for the 20-foot demarcation of the nearby electrical lines as required by Manual 80 , Procedure 10. A Time Out was taken upon discovery and the work suspended.

Further evaluation revealed the requisite controls were not incorporated into the work execution document. During the walkdown, the overhead power lines and limitations for use of the aerial lift (outside of Manual 8Q, Procedure 10 controls) were discussed. This was interpreted and incorporated into the work package as "No electrical hazard existed."

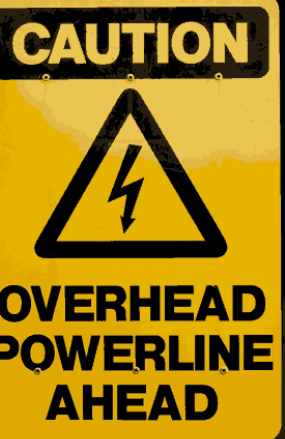

SRS issued a First Alert to notify management and personnel of an issue where the second barrier per Manual 8Q, Procedure 10, Requirements for Working Near Overhead Electrical Lines, Critical Piping, Poles, Towers and Guy Wires, was not in place when work was performed. First Alerts are prepared based upon preliminary information in order to rapidly communicate important safety-related information in the interest of preventing similar events and may be revised following analysis of additional information.

The Alert identified two lessons that personnel need to be reminded of: (1) Work near electrical power lines needs to be conducted per Manual 8Q, Procedure 10. For this event, the second barricade was not in place for designating the line of demarcation to stay greater than 20 feet from the electrical lines and precautions were not taken to isolate additional electrical lines. (2) The assignment and performance of the Point of Contact did not meet facility management's expectations.

\section{Labeling 3R Lasers and LED Devices}

Lesson 2014-1728 (Blue - Information)

Recently, a facility operations technician at INL's ATR facility contacted the INL Laser Safety Officer (LSO) about labeling on some recently purchased multi-function flashlights that contain a $3 R$ laser. The items ordered were Streamlight Twin-

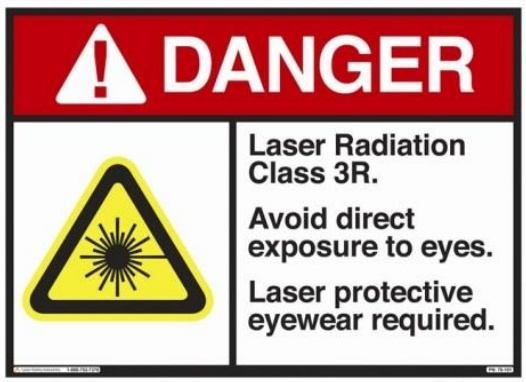

Task 3AAA LASER LED and Multi Ops flashlights. The technician explained that the "Caution" label identified it as a 3R/2 laser/LED with an output $<55 \mathrm{~mW}$, and wondered if they

could still use the devices. The LSO recognized that Class $3 R$ lasers should have "Danger" labels and be $<5 \mathrm{~mW}$. The technician was instructed to remove the flashlights from service until further information was gathered to determine if the units were safe for use.

After physically examining the flashlights and obtaining a photo of the label, the INL LSO discovered that IEC/EN 608251, the International Electrotechnical Commission/European standard for Safety of Laser Products, uses the terms 'laser' and 'LED' interchangeably, although LEDs are not lasers, nor do they have the same optical properties as lasers.

A Light Emitting Diode (LED) is defined as any semiconductor p-n junction solid state device which can be made to produce electromagnetic radiation by radiative recombination in the semiconductor in the wavelength range from $180 \mathrm{~nm}$ to $1 \mathrm{~mm}$. (The optical radiation is produced primarily by the process of spontaneous emission, although some stimulated emission may be present.) In simple terms, it is a basic pnjunction diode, or two-lead semiconductor, which emits light when activated.

The INL LSO contacted Streamlight and was told they were aware of the concern, but did not have any other labels to provide. The flashlights are manufactured and labeled in China. The INL LSO could find no labeling requirements for LEDs in the U.S., other than what is required by 16 CFR Part 
305.15, Energy and Water Use Labeling for Consumer Products under the Energy Policy and Conservation Act, and the labels affixed to the flashlights have nothing to do with this regulation. The FDA regulations (21 CFR 1040.10 and .11) are only applicable to lasers. The remaining parts (21 CFR 1040.20 and .30) are only applicable to sunlamp/UV and mercury vapor products. So, in accordance with FDA regulations, the $3 \mathrm{R}$ laser function of these flashlights should have a "Danger" label with a maximum output of $<5 \mathrm{~mW}$ indicated.
The lesson that can be learned from this situation is to be inquisitive and have a questioning attitude to ensure that the proper subject matter experts are engaged when questions regarding a products safe use arise. Laser pointer devices must be labeled correctly to properly communicate hazards to the user. Devices found with improper or illegible labels must be evaluated and relabeled to ensure they meet federal requirements and are safe for use.

\section{$1^{\text {st }}$ Qtr FY-15 IDENTIFICATION OF RECURRING EVENTS}

Contractors and DOE have struggled for some time defining a process for determining if an event or condition is recurring. DOE Order 232.2 is not very prescriptive in aiding categorization of recurring events - which is the way it should be, but without some guidance to follow, a consistent approach to identifying recurring events cannot be realized. To address this deficiency, the ORPS Subgroup of the EFCOG Integrated Safety Management \& Quality Assurance Working Group developed a worksheet and corresponding flowchart to help managers and program owners walk through a logical process to arrive at a conclusion on whether an event or condition is recurring or not recurring.

During the $1^{\text {st }}$ Qtr FY-15, INL began a pilot program to test the effectiveness of the worksheet/flowchart. The pilot will continue until March 10, 2015, at which time all comments will be addressed and the worksheet/flowchart will be modified accordingly. The worksheet/flowchart will then be sent for review to be incorporated into an existing INL procedure or will itself become a controlled document.

\section{Attachment 1 Recurring Event Flowchart}

awly discovered events, conditions, and increasing trends (see definitions) should be reviewed for potential categorization as an ORPS ecurring event. Areas of stable performance should also be reviewed periodically to determine if the current level represents an acceptable isk, as determined by management. The analysis must include both reportable AND non-reportable events and conditions.

Ultimotely the determination of whether a recurring event is warranted is a management decision. The answers in this flowchart can be used to present the logic of that determination to manogement and to external customers (DOE).

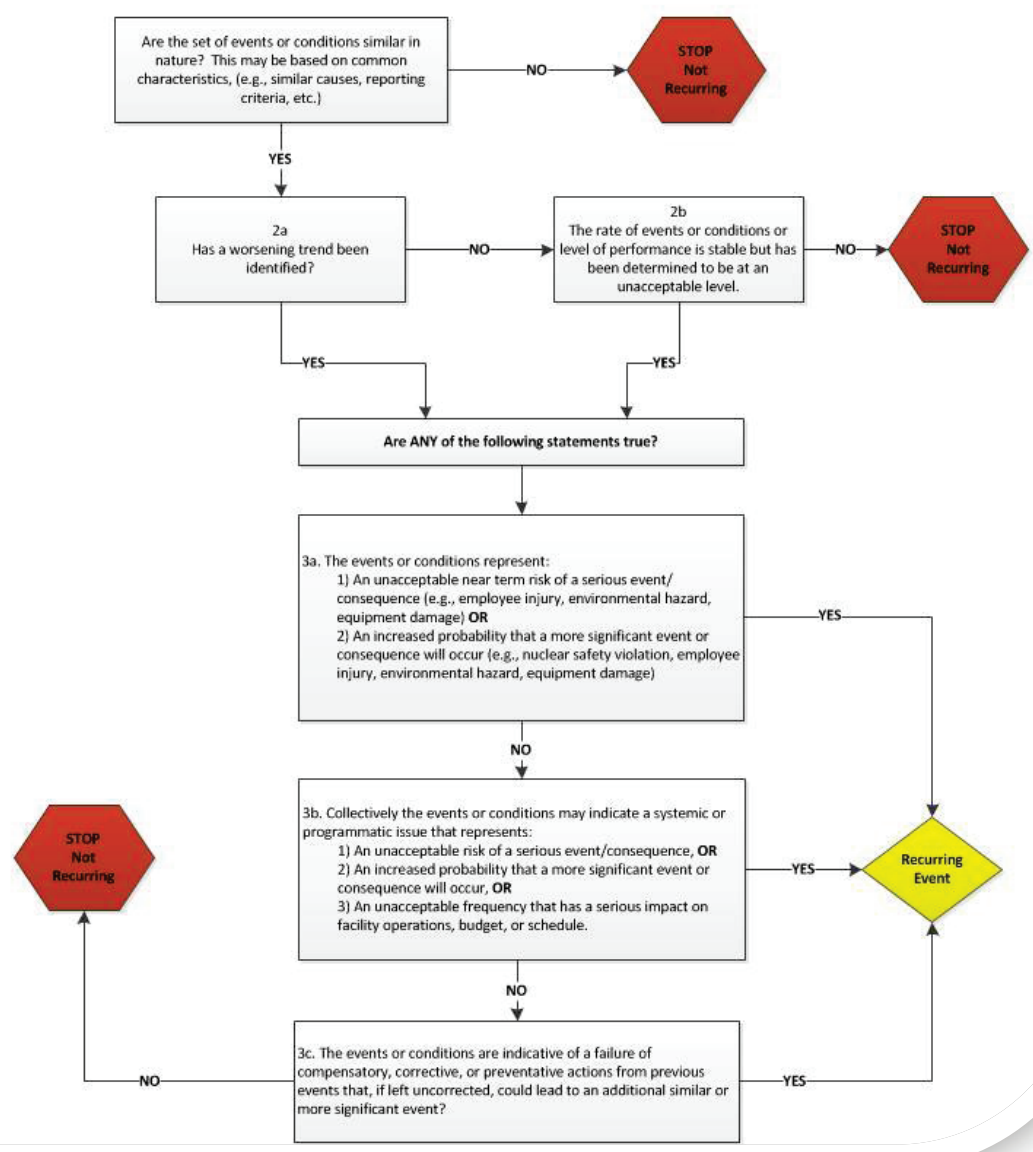




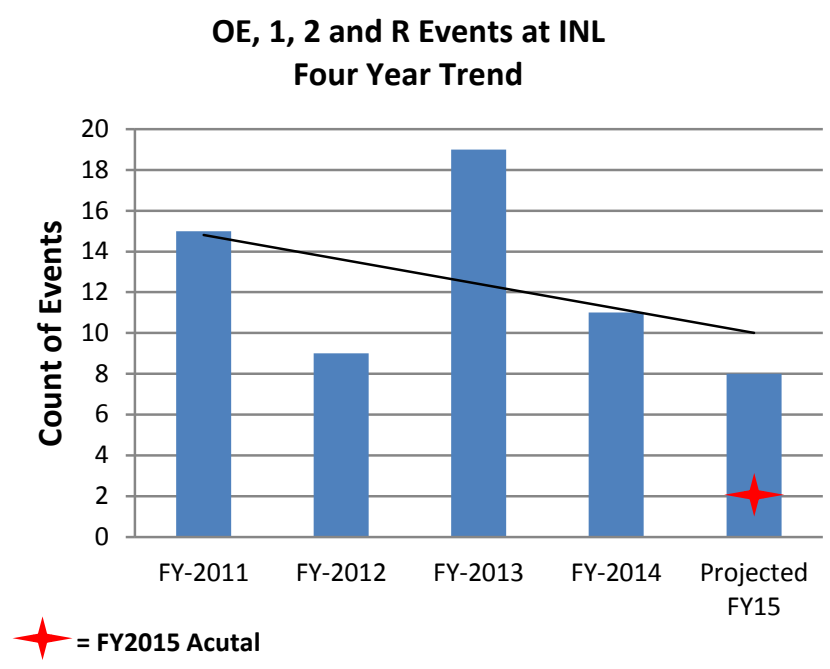

Significance Category $\mathrm{OE}, 1,2$, and $\mathrm{R}$

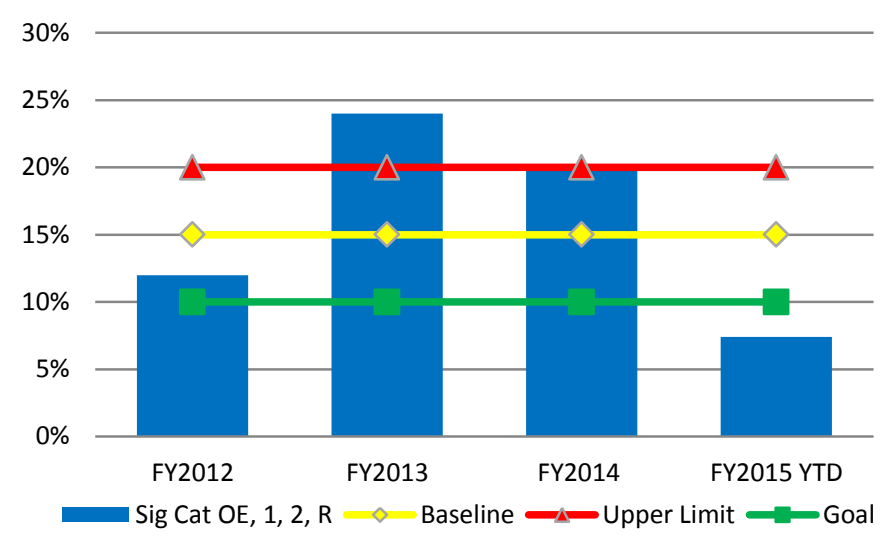

INL established a set of performance metrics to monitor events by their significance. The measures compare INL events to those reported at other facilities within the DOE complex. Baseline data was derived from complex wide reporting of 5,630 events in the ORPS database between 2009 and August 2014. Control Limits are for Significance Category $O E, 1,2$, and $R$ events were set at $+5 \%$ of baseline. This metric tracks/trends the distribution of reportable events by significance and shows the significance of events occurring at the INL since FY-11.

As shown in the first chart to the left, INL is experiencing a downward trend in the number of significant events (Sig Cat $\mathrm{OE}, 1,2$, and R) occurring at the INL over the past four years. If the current rate continues through the Fiscal Year, INL will again see fewer significant events than reported last fiscal year.

During FY-13 and FY-14, INL reported a greater percentage of significant reportable events (Sig Cat OE, 1, 2, and R) as compared to other DOE facilities (see next chart). However, FY-15 data shows the INL to be below our goal of less than $10 \%$ of events reported at INL as significant events.

In addition, The INL is experiencing a slightly lower percentage of Significance Category 3 events than those experienced throughout the rest of the complex, and, during the $1^{\text {st }}$ quarter FY- $15,74 \%$ of INL reportable were categorized as Significance Category 4 events. This is higher than the complex average of $42 \%$.

Additional analysis on how INL measures up to the balance of the complex in each of the reporting criteria groups is provided throughout this report. 
There were no operational emergencies reported during the $1^{\text {st }}$ quarter of FY-15. The last operational emergency was reported in April 2012, when boron triflouride gas leaked from a neutron detector (NE-ID-BEA-INLLABS-2012-0003). The rate of occurrences of operational emergencies continues to trend at zero.

When compared to the balance of the DOE complex, the rate of occurrence of these types of events at INL is consistent with those reported elsewhere. So far in FY-15, only one Operational Emergency was reported throughout the DOE Complex, equating to less than $1 / 2$ of a percent of the total events reported. The INL is consistent with the rest of the DOE Complex in that none ( $0 \%)$ of INL events were reported in the Group 1 reporting group.

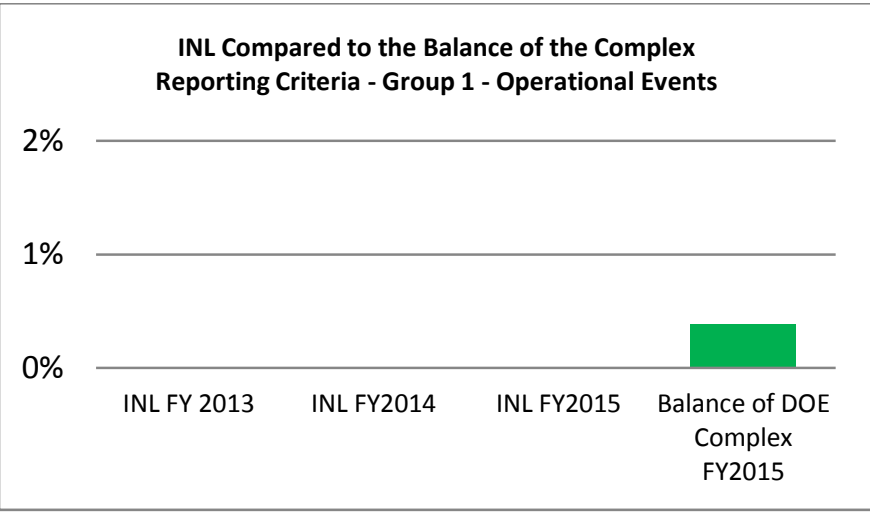

\section{$1^{\text {st }}$ Qtr FY-15 GROUP 2 - PERSONNEL SAFETY AND HEALTH}

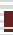

\section{TREND SNAPSHOT}

Personnel Safety and Health Events: During the $1^{\text {st }}$ Qtr FY-15, six events occurred that were related to personnel safety and health (e.g., occupational injuries, occupational exposures, fires, explosions, or hazardous energy) and were communciated to DOE through ORPS. Six additional events were reported via INRs or directly into LabWay that did not meet the ORPS thresholds but were related to criteria in this reporting group. The rate of occurrence of reportable personnel safety and health events is trending upwards following two quarters of a high number of events in this reporting group.

During the past twelve months, there have been 18 events reported under this reporting criteria. Four resulted in personnel injury, one was due to an unexpected contact with a hazardous energy source, six with discovery of an uncontrolled hazardous energy source, and seven were the result of a failure to follow the hazardous energy control process.
When compared to the balance of the DOE complex, the rate of occurrence of Group 2 events at INL was slightly higher than those reported elsewhere in the complex during FY-15. In FY-15, 22\% of INL's reportable events were reported under Personnel Safety and Health criteria. In comparison, $20 \%$ of those reported across the DOE complex fell into this reporting group.

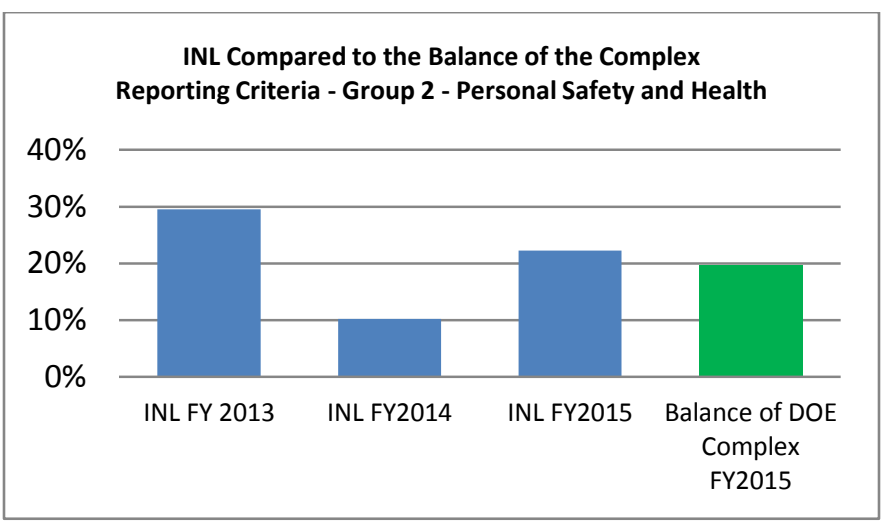

Personnel safety and health occurrences were the second most frequently reported event type, accounting for 18 reportable events in the last 12 months. Six events categorized under the personnel safety and health reporting criteria were reported during the $1^{\text {st }}$ Qtr FY-15. These are summarized below. Additionally, 11 non-reportable events were also documented in the INL issues management 
software or reported via INRs during the current quarter. A summary of these events is also provided.

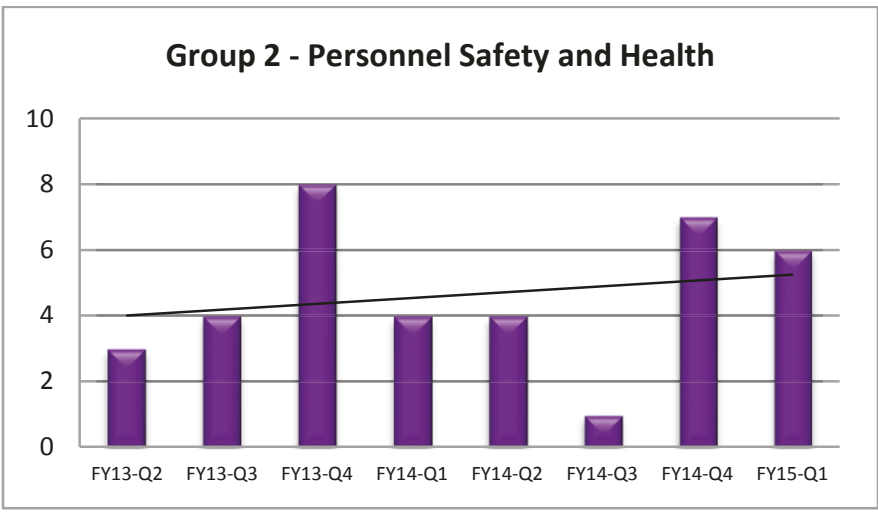

Injury While Moving Fire Rated Lateral File Cabinet NE-ID--BEA-MFC-2014-0008 (Significance Category 3) On 10/3/14, a heavy equipment operator was part of a fiveman crew moving a fire rated lateral file cabinet when he injured his left arm. The crew was sliding the cabinet into place after removing it from a pallet jack when the employee experienced a 'pop' in his left forearm. Afterward, he experienced a burning type pain from his elbow to forearm and occasionally extending up to his shoulder.

Prior to the injury, a maintenance work request had been submitted to have the file cabinets moved from MFC-717 into the basement of MFC-752. Based upon the screening criteria in INL's work control procedure, the work was screened as

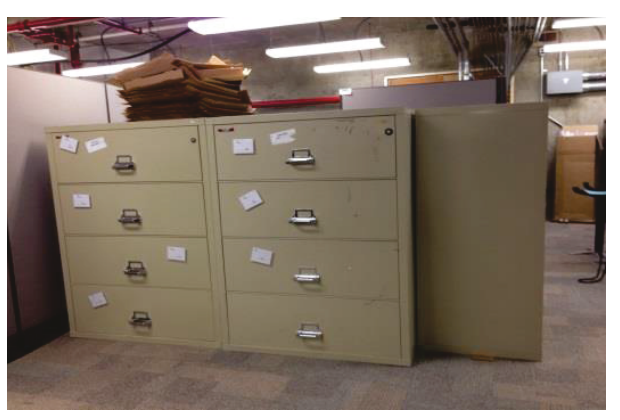
minor maintenance. A discussion and planning of the work was performed. In response, the cabinets were placed on a pallet jacket and moved into a furniture-moving box. The box was then moved by forklift to a basement entryway at MFC752 where it was lowered by crane into MFC-752. The cabinets were then placed onto another pallet jack to be moved to the final location where they were manually slid into place the final three to four inches. The cabinet in question was empty and weighed 750 pounds.

This event stresses the importance of considering all aspects of work involving moving of heavy equipment. In this case, the final move of three to four inches proved to be an opportunity for injury. Alternative methods of moving heavy equipment should be considered and implemented if possible.

\section{Lockout/Tagout Lock-box Hasp Not Fastened} NE-ID--BEA-ATR-2014-0028 (Significance Category 4) On 10/7/14, a DOE Facility Representative (FR) noted that the hasp for a Lockout/Tagout (LOTO) lock-box was not properly fastened. The FR immediately notified the ATR Control Room Supervisor (CRS). A check was performed to confirm that work under the control of the LOTO was not in progress. A certified operator and Shift Supervisor verified that all required keys were present in the lock-box. The LOTO was walked down to verify that all isolation components were locked in the position required by the LOTO. The lock-box was properly locked. All other lock-boxes in ATR and the utility area were verified to be locked correctly.

Attention to detail could have prevented this event had responsible personnel properly verified the lock- box was secured after placing the locks inside.

\section{Unexpected Discovery of an Uncontrolled Hazardous Energy Source - No Injuries}

NE-ID--BEA-SMC-2014-0003 (Significance Category 3)

During a pre-job briefing to replace the controller for an air handling unit at SMC, attendees identified that the instrument air supplied to the controller was not identified as a hazardous energy source for the LOTO, even though the air was addressed in the hazards and mitigations table of the work order. This was discovered prior to executing the LOTO.

During a team discussion, personnel identified that this same activity had been previously performed on other air handling units using electrical LOTO isolation only, without consideration of the air as a potential hazardous energy source. A solenoid valve, which closed with the loss of power allowing the line to vent, isolated the instrument air, preventing exposure to the workers. However, since the previous LOTO did not consider whether the solenoid was an adequate isolation point nor was zero energy verification performed on the instrument air, this discovery was categorized as an unexpected discovery of an uncontrolled hazardous energy source.

This event did not result in an actual exposure to hazardous energy; however, those involved in preparing and executing the LOTO did not consider whether the low pressure air was a hazardous energy source that should have been locked out or whether the solenoid valve would provide sufficient protection, nor was the lack of energy verified. 


\section{Electrical Ground Fault During Cleaning of Extrusion Press}

NE-ID--BEA-EFF-2014-0001 (Significance Category 3)

On 11/26/14, an electrical ground fault occurred at the

Experimental Fuels Facility (EFF) during cleaning of an

Extrusion Press. Copper billets were heated in a molten salt

bath then

extruded. The

extrusion

press requires cleaning after

each

extrusion due

to the salt

buildup inside

of the

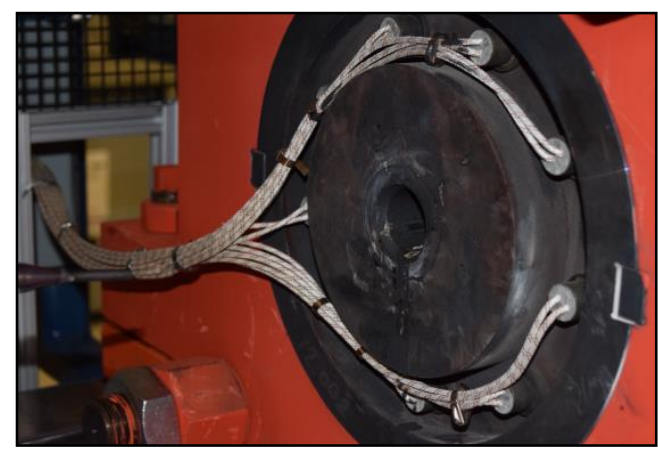

container block. A wire brush was used to remove debris and then a cotton brush and water for salt removal. Excess water from the brush ran down the front of the container block and onto the container block heater wire insulation.

Soon after the water contacted the wire insulation, a Science and Technology (S\&T) Technician observed a flash and a loud popping noise. Initial investigation did not disclose any energized conductors that could have resulted in an electrical short. Upon further investigation, it was determined by design that the Dinamite contactors for both the container heaters and the die heaters have a "pass-through" on the middle pole (i.e., they do not open when control power is turned off). This allows voltage to the heaters but does not allow for a completed circuit which prevents the heaters from heating up.

An investigation found that the cleaning water and salt had seeped through the wire insulation causing a ground fault which resulted in a $40 \mathrm{amp}$ fuse for the heaters to be blown although the heaters were in the off position. The Extrusion Press was placed in a safe configuration, de-energized, and tagged out of service.

Both the vendor supplied data and the procedure were ambiguous on how to clean the container block. The Hazards Table in the procedure did not identify dripping salt water or lubrication onto the heater lead wires with permeable insulation as a hazard. As such, it was not recognized that the heater wiring would be subject to an environment for which it was not intended.

\section{Lockout/Tagout Installed by Personnel with Expired Qualification}

NE-ID--BEA-IMCL-2014-0001 (Significance Category 4)

A LOTO was prepared and reviewed (round-tabled) in support of preventative maintenance on Exhaust Fan BEX-EF-002.

During the preparation of the LOTO, the facility Shift Supervisor (SS) recognized that the LOTO qualification for the employee designated to install the LOTO was going to expire at the end of the week. Based on discussions with the Training Organization, the SS understood that a 30 day extension would need to be processed to continue the qualification until a training class could be set up.

The following week the LOTO was installed by the SS and the Irradiated Materials and Characterization Laboratory (IMCL) operator. The preventive maintenance work was then released by the SS. A question was asked about the status of the LOTO qualification extension and it was determined that the extension had not been processed before the qualification expiration date. At the time of discovery, maintenance personnel had already completed work on the fan.

IMCL Management recognized that the operator's LOTO qualifications were due to expire within the week, and they initiated the process to grant a temporary extension of the employees qualification; however, they did not follow through and ensure the extension was granted prior to making an assignment requiring LOTO qualifications.

\section{Lockout/Tagout Process Not Followed When Connecting Electrical Power to a Trailer} NE-ID--BEA-CFA-2014-0005 (Significance Category 4) On $12 / 23 / 14$, it was discovered that a construction contractor mobile trailer had been connected to a power panel without following a hazardous energy control process described in Laboratory Wide Procedure (LWP)-9400. A CFR gave direction to connect a $240 \mathrm{v}$ single phase power cord to the power panel. The fuse supplying power to the pole mounted transformer had not been installed for some time. No electrical energy was present. A LOTO or clearance was not in place during the work activity.

Personnel must ensure that they perform work within the controls established at INL. In this event, these controls include those established for both LOTO and subcontracted work.

\section{CO-2014-5382}

On 11/18/14, a worker was excessing an arbor press out of MFC-796. The press had been banded to a particle board 
pallet by another DOE Subcontractor. The press was being moved with a manual pallet jack. As the pallet jack was being pushed out the door of the facility, its wheels contacted the north facility apron threshold causing the load to shift forward. As the load shifted, the banding failed and the press fell forward off the pallet jack.

The workers placed the press onto another pallet on the apron and it was moved to the excess yard. After the event, the worker informed the Laboratory Space Coordinator about the incident.

DOE recently published a Lessons Learned on the dangers of material handling (see the Lessons Learned section above).

DOE shared that recent DOE events demonstrate the importance of adequate hazard analysis, walkdowns, and detailed pre-job briefings for material handling. More than 200 material handling events reported to the ORPS from January 1, 2010, through August 31, 2014, were reviewed to determine common factors and identify lessons learned.

A copy of the lesson can be read here: https://opexshare.doe.gov/lesson.cfm/2014/10/27/4594/Losi ng-Control-Material-Handling-Dangers

\section{CO-2014-5474}

On $11 / 24 / 2014$, a maintenance carpenter was assisting a painter in moving three metal doors out of a paint booth. While lowering the second door to the floor, the carpenter noticed a twinge in his lower back. The next day, he experienced pain in his back and informed his manager. He was directed to Medical, where he was sent to CFA for further evaluation.

An evaluation of the work found that nothing improper was done in performance of moving the door. Supervision discussed with personnel involved in the task, that, as we age, we need to be more careful and cognizant of how we perform simple tasks. Tasks that have never caused any issues in the past may, in fact, cause issues as we age. Proper stretching and lifting techniques can minimize the probability of injury in situations such as this.

\section{CO-2014-5543}

A health physics technician was loading samples into sample counter and entering data on computer when he felt pain in shoulder and numbness radiating to his right fingers.

Frequent breaks from tasks can help prevent injuries caused by repetitive motion.
CO-2014-5807

On 12/14/14, CFA Fire Station Personnel were filling Self Contained Breathing Apparatus (SCBA) bottles with the CFA1611 breathing air compressor when an electric solenoid valve separated between the brass housing and the electric coil, causing a loud "bang." The separation caused the valve components to be forcibly expelled.

Fire Department personnel pressed the emergency stop button and safely shut down the compressor. The compressor was tagged out-of-service and the Safety Significant Component Engineer began working with the manufacturer to identify and correct the failed component.

This event demonstrates that personnel must always remain alert and must expect the unexpected. When working around hazardous energies, ensure that you are in a safe location and that others are safe from harm if things go wrong.

\section{CO-2014-5903}

During the installation of a new mass spectrometer (MS) in a laboratory at INL Research Center (IRC), a LOTO was requested to support vendor installation and testing activities associated with the accelerator device which is part of the MS. The requested LOTO support included the isolation of four cords with plugs. The testing activity required two individuals to be in the exclusion area at the same time.

The Facility Area Supervisor (FAS) determined that all four plugs could be safely isolated in one clam shell device. The FAS developed the LOTO as a "simple" LOTO per LWP 9400. The Lab Space Manager questioned the "simple" LOTO and initiated a stop work to evaluate the need for a "complex" LOTO per LWP-9400.

The subsequent evaluation determined the LOTO did not meet all the criteria for a "simple" LOTO, per INL procedures. No exposure to uncontrolled energy or loss of exclusive control of the four cords occurred. This event stresses the importance to question that which does not seem appropriate. By doing so, an administrative error in the application of a LOTO was identified before any work took place and any safety was compromised.

\section{LP-CO-2014-0766}

On $11 / 13 / 14$, BEA technicians were preparing to perform elevated work using a bucket truck at the Idaho Nuclear Technology and Engineering Center (INTEC). During the work preparation, the technician opened the door to the truck cab 
and witnessed smoke and fire coming from the inside of the vehicle. The technician shut down the vehicle and work was stopped. The INL Fire Department was notified and responded. The fire was extinguished before Fire Department arrived. Again, this event stresses the importance of being prepared for the unexpected. Knowing what to do when things don't go according to plans can help prevent a situation from becoming worse.

\section{SMC-CO-2014-1229}

An operator was tasked with placing a nearly empty portable diesel fuel tank into the back of a pickup truck using a forklift. The tank was banded to a pallet, but the operator found that the pallet would not fit between the wheel wells of the truck bed. The operator and a supervisor took a timeout and consulted with the hoisting and rigging and forklift technical point-of-contact and determined that the tank would fit into the truck without the pallet and that the tank was light enough to be safely transferred from the pallet to the pickup bed by two people.

The team made the decision to position the forklift and pallet from the side to allow the tank to be slid into the bed of the pickup from the pallet. They performed a brief and a spotter and a supervisor controlled the area. The team cut the banding holding the tank to the pallet and the operator raised the pallet high enough to clearly see the bed of the truck. When lowering the load, he inadvertently tilted the forks, causing the load to tip forward. The slight forward motion of the tank caused a small amount of residual fuel within the tank to shift. The momentum of the fuel caused the tank to slide off the pallet, roll, and break the back window of the pickup. There was no other damage to the vehicle and no personnel were injured.

\section{$1^{\text {st }}$ Qtr FY-15 GROUP 3 - NUCLEAR SAFETY BASIS EVENTS}

\section{TREND SNAPSHOT}

Nuclear Safety Basis Events: Three nuclear safety basis events were reported in the $1^{\text {st }}$ Qtr FY-15. The rate of occurrence of nuclear safety basis is trending slightly downward over the past two years. During the past 12 months, 11 events have been reported under this criteria; ten of which were identifed at ATR and one at MFC. ATR has had three noncompliances to Technical Safety Requirments (TSRs) and/or Limiting Conditions of Operations (LCOs) and six events where a positive unreviewed safety question (USQ) was declared. Both ATR and MFC had one event, each where a USQ determination was negative. An analysis of the six ATR positive USQs events did not reveal any commonalities. Discovery of the conditions has been the result of increased rigor in evaluating existing safety analysis at ATR and identifying legacy problems with the analyses.

When compared to the balance of the DOE complex, INL has been reporting a higher percentage of reportable issues in the Group 3 - Nuclear Safety Basis, than the rest of the complex; however, that rate fell this quarter due to an increase in the number of events reported in Group 4- Facility Status. The events reported at INL are not unexpected and are attributed to increased rigor in assessing safety of the ATR. This rigor is in response to lessons learned from the Fukushima accident in Japan and attributed to hiring a new group of safety engineers with a fresh set of eyes. Currently in FY-15, 11\% of INL's reportable events were reported under Nuclear Safety Basis criteria compared to $17 \%$ across the DOE complex. 


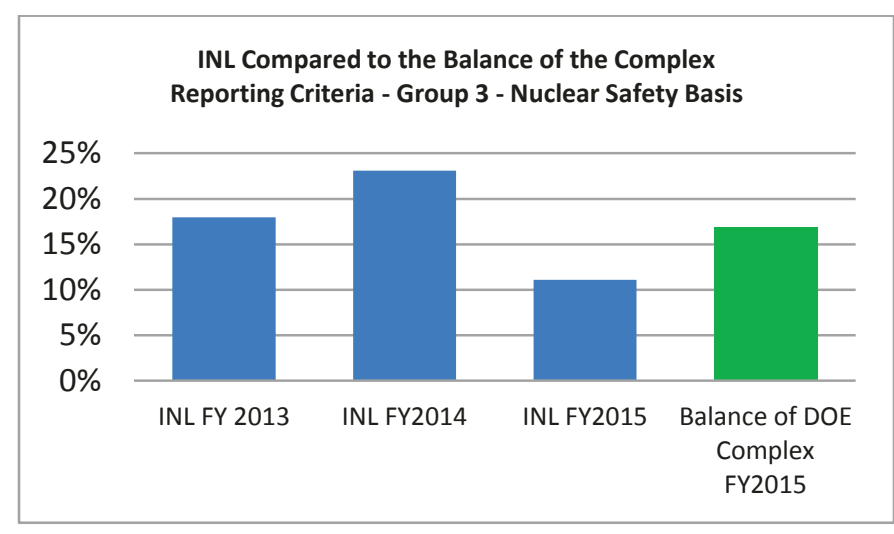

The number of events reported under the Nuclear Safety Basis criteria is trending downward over two years. In FY-15, Nuclear Safety Basis events have been the fourth most frequently reported event type at INL, accounting for three reportable events this quarter, and 11 in the past 12 months. The three events were reported during the $1^{\text {st }}$ Qtr FY-15 and are summarized below.

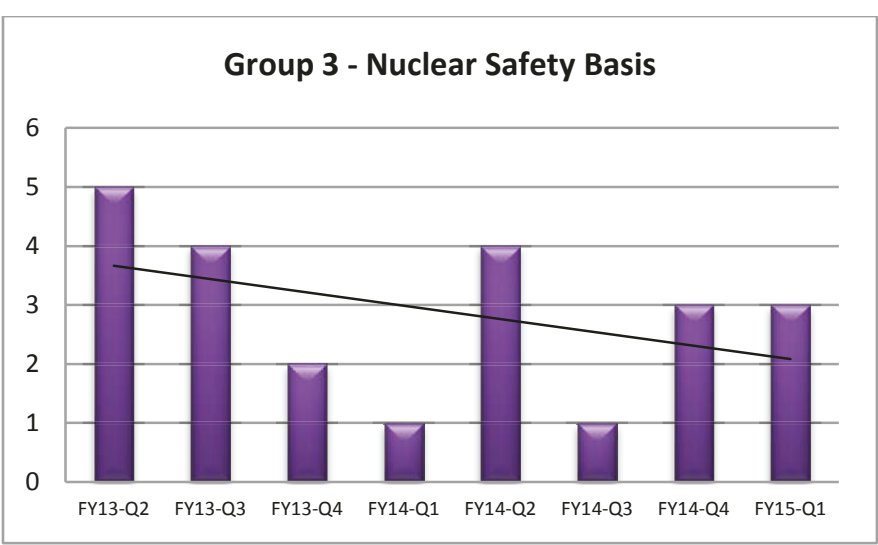

Window 5M F-Slab Cracked Resulting in PISA

NE-ID--BEA-HFEF-2014-0005 (Significance Category 4)

At the Hot Fuel Examination Facility (HFEF) on 10/25/14, the

hot cell window $5 \mathrm{M}$ F-slab was cracked during an oil drain/fill operation. The window had been drained and the filling process was almost complete when a loud pop was heard. The personnel performing the operation noticed that the Fslab of the window was severely cracked with oil slowly leaking out of the cracks. The operators, under engineering advisement, drained the oil out of the window to prevent the possibility of the glass breaking out of the window and releasing the oil into the operating corridor.

HFEF windows are made up of multiple slabs of glass. Both the $A$ and $F$ slabs serve as protective or cover glass for the shielding slabs $B$ thru $E$ in between. Window $5 \mathrm{M}$ in cell window seal (B-slab) has been identified to leak small amounts of oil into the main cell. The windows in the HFEF main cell are considered as safety significant for the main cell confinement boundary and for shielding. With the seal on the F-slab broken and the suspect seal on the B-slab there is a potential leak path for air to enter into the main cell, rendering the $5 \mathrm{M}$ window in a configuration that is not prescribed in the DSA or the supporting documentation. In addition, the impact of the windows current configuration on the frequency of a confinement breach that has been established in the safety basis needs further evaluation.

Operations personnel established the Main Cell REPAIR MODE as an interim control and a PISA reasonability determination was performed which screened positive. The Unreviewed Safety Question Determination (USQ-D) was completed. The USQ-D determined that the window's configuration did not increase the frequency of an accident previously evaluated in the safety basis because the actual primary confinement boundary of the cell at the window interface is provided by the B-slab, and the F-slab fracture does not affect the probability of the B-slab failure.

Additionally, DSA-003-HFEF, "HFEF Safety Analysis Report", allows for small amounts of air in-leakage through the confinement boundary, and, therefore, the configuration does not deviate from the confinement system functional requirements in the DSA. The window also does not rely on the F-slab for performance in compliance with the shielding safety function established in the DSA. The USQ-D establishes that there is no USQ associated with the $5 \mathrm{M}$ window cracking, and the interim controls established in the PISA reasonability determination are no longer required. An evaluation of the safety of the situation (ESS) was developed and transmitted to DOE. Based upon this new information, the occurrence report was updated to a 3B(3)SC4.

\section{Declaration of Positive USQ Concerning Fueled Experiment Storage in the ATR Vessel} NE-ID--BEA-ATR-2014-0033 (Significance Category 2) On 12/3/14, a Potential Inadequacies in the Safety Analysis (PISA) was declared regarding fueled experiment storage in the ATR reactor vessel. The ATR facility safety basis, Safety Analysis Report (SAR)-153/TSR-186, specifies requirements for the protection of fuel elements in the reactor vessel in order to prevent an inadvertent release of radioactive material during all modes of reactor operation and during handling and storage in the ATR canal. However, the safety basis does not specify similar requirements for the protection of fueled experiments.

The ATR experiment safety analysis process evaluates the risks involved with irradiation of experiments in the ATR and 
the potential radioactive material releases that could occur during reactor operation and during transfer and storage in the ATR canal. Fueled experiments may have a radioactive material inventory large enough to present a risk to the workers and the public. During reactor operation, required safety systems and controls established for the protection of fuel elements may be relied upon for the protection of fueled experiments; however, during reactor outages, fueled experiments may remain in the ATR reactor vessel after the fuel elements have been removed.

The ATR safety basis does not address this scenario by requiring protective safety system operability or controls based on experiment requirements. Consequently, an accident, such as a shutdown loss of coolant accident, could potentially damage an irradiated fueled experiment and result in an inadvertent release of radioactive material.

Following identification of the condition, interim controls were established to protect fueled experiments in the reactor vessel. An investigation is ongoing - following the investigation, corrective actions will be identified and implemented.

\section{Declaration of Positive USQ Concerning ATR} Experiment Loop Pressurizer Seismic Vulnerability NE-ID--BEA-ATR-2014-0036 (Significance Category 2) On 12/15/14, a PISA was declared concerning ATR experiment loop pressurizer seismic vulnerability. The Chapter 15 safety basis accident analyses assume that experiment loop leakage will be limited during a Condition 4 seismic event and would be bound by a $1 / 2$-inch heater drain manifold break simultaneously occurring in each experiment loop. Preliminary evaluation of the experiment loop 2E-NW pressurizer support structure indicates the pressurizer is vulnerable to collapse during these postulated seismic events which may not be bound by the safety basis analysis.

The ATR had been shut down due to a through wall leak in a heater leg on the experiment loop 2E-NW pressurizer. Planning for the replacement of the pressurizer initiated a review of the original installation and subsequent seismic evaluations. The review identified that the experiment loops were evaluated to seismic criteria in place around 1975; however, available documentation was inadequate to conclude that the pressurizer supports are robust (seismically) as stated in the analysis.

Preliminary evaluation of the $2 \mathrm{E}-\mathrm{NW}$ pressurizer also concluded that the support structure may be vulnerable to collapse during a seismic event. The pressurizer support structure for other experiment loops may be similarly vulnerable to a seismic event. The accident analysis for a seismically initiated rupture of the experiment loops assumes that leakage could occur but that catastrophic failure of an experiment loop would not occur. Therefore, the accident analyses presented in SAR-153, Sections 15.4.7, 15.6.6, and 15.7.1 were reviewed to identify any assumptions made with regard to the experiment loops.

An investigation is ongoing - following the investigation, corrective actions will be identified and implemented.

\section{Other Non Reportable Events}

There were no additional non-reportable events related to nuclear safety basis problems reported in LabWay during the $1^{\text {st }}$ Qtr FY-15. 


\section{TREND SNAPSHOT}

Facility Status Events: Facility status events accounted for $48 \%$ of the events reported in the $1^{\text {st }} Q \operatorname{tr} F Y-15$. The number of events reported under this criteria nearly doubled from last quarter. The rate of occurrence of facility status events is trending upwards over the past two years. Over the past 12 months, 28 events have been reported at the INL under this reporting criteria. ATR has reported 19 of them, MFC has reported eight, and SMC has reported one. Four events at ATR were attributed to a performance degradation of a safety class or safety significant structure, system, or component when the system was required to be in operation. None of these were related to the same equipment. Additionally, 13 events at ATR were related to performance degradation of a safety class or safety significant structure, system, or component when the system was not required to be in operation. Many of these are identified during reactor shutdown.

During the $1^{\text {st }}$ Qtr FY-15, MFC was undertaking a concerted effort to identfy suspect/counterfeit parts, and the three events were a result of that effort. Although the three events were similar in that they were issued following discovery of suspect/counterfeit parts at MFC, they do not warrant reporting as recurring.

The percentage of occurrence of Group 4 events at INL is higher than that of the balance of the DOE Complex ( $48 \%$ vs $17 \%$ in the $1^{\text {st }} \mathrm{Qtr} F \mathrm{FY}-15$ ) and has shown an increase since FY13. Almost half of the Group 4 events in FY-14 were related to performance degradation of a Safety Class or Safety Significance Structure System or Component.

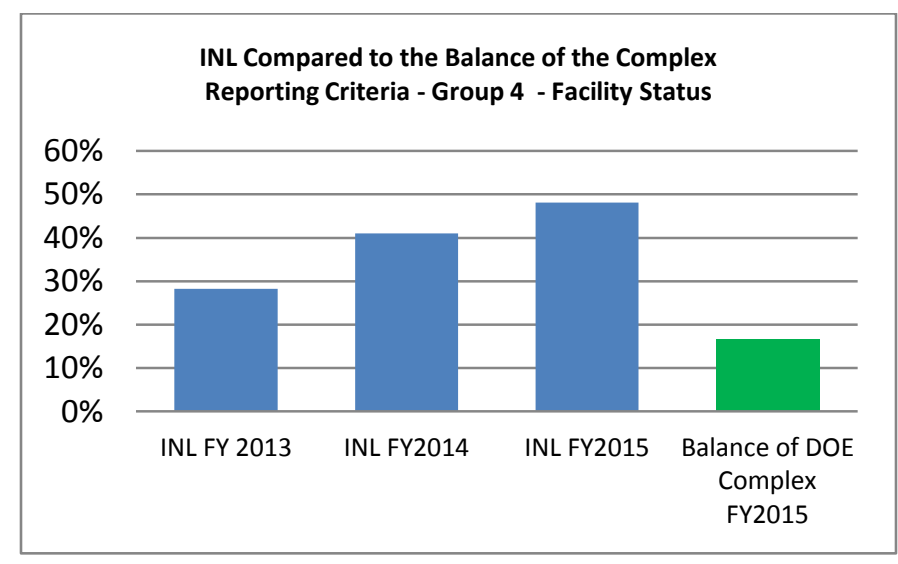

Events related to facility status have been the most frequently reported event type, accounting for 28 reportable events in the past 12 months. During the first quarter of FY15, there were nine events reported under criteria $4 A(2)-$ Performance degradation of any Safety Class Safety Significant Component (SSC) when it is not required to be operable. These nine equipment problems were found during the ATR reactor turnaround.

Based on the above data, the Office of Nuclear Assurance and ATR Management have identified concerns regarding the potential that such failures could occur during reactor operations when the SSCs are required to be operable, and could impact nuclear safety. Safety significant components are identified as High Critical Components, and failures are tracked through the ATR Equipment reliability process. This classification carries through to both the Issues Management and Work management processes to ensure these equipment failures are appropriately understood and corrected. As such, during investigations into $4 \mathrm{~A}(2)$ events, ATR management is also reviewing the equipment reliability index for the associated equipment. This additional review will give operations management the ability to look back in time to see if problems were occurring that may have indicated pending failure. 


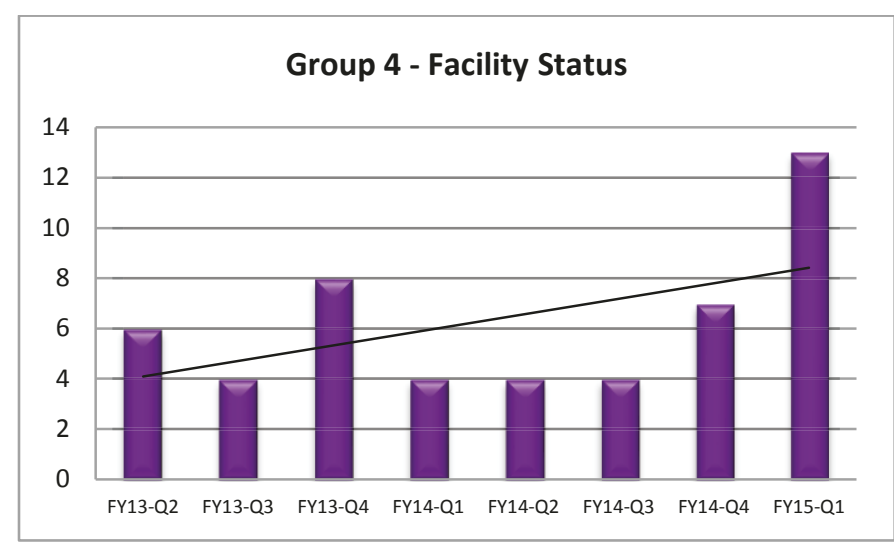

Thirteen events were reported under the Group 4 - Facility Status criteria during the $1^{\text {st }}$ Qtr FY-15 and are summarized below.

\section{ATR Wide Range Neutron Level (WRNL) Channel "A" Failure}

NE-ID--BEA-ATR-2014-0030 (Significance Category 4) On 10/1/14, the ATR operator at the controls (OATC) noted that wide-range neutron level channel A output had dropped to zero with occasional spikes. The OATC informed the Control Room Supervisor and Reactor Instrument Control Technician to investigate.

At the time of wide range neutron level channel A failure, the ATR was in outage with fuel removed from the reactor vessel. Consequently, wide range neutron level channel $A$ was not required to be operable. Initial evaluation was that this equipment failure was not reportable due to the redundant channels available when the instrumentation is required to be operable.

On $11 / 11 / 14$, ATR management determined that this instrument failure met the definition of performance degradation and declared the instrument failure reportable. ATR TSR-186 LCO 3.2.3.3, LOCA PCP Shutoff System was not required to be operable at the time the wiring discrepancy was noted.

\section{Large Door Lock Inadvertently Lifted out of Pivot Mount}

NE-ID--BEA-HFEF-2014-0003 (Significance Category 4)

On 10/10/14, during operations to transfer material between the HFEF Main Cell and the Decontamination Cell, the Large Lock Door was inadvertently opened too far and was lifted out of the door pivot mounts. As a result, the Large Lock Door swung out of place and could not be placed back into its pivot mounts and closed using currently existing procedures.

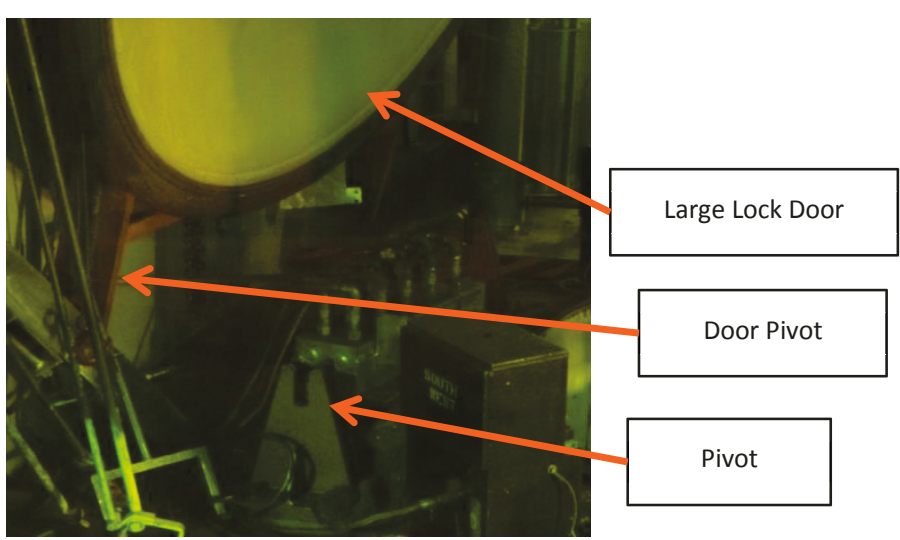

The Large Lock Door is credited in the HFEF SAR as part of the Safety Significant Confinement Boundary for the HFEF Main Cell. The inability to close the Large Lock Door means the confinement boundary of the Main Cell cannot be reestablished using currently existing procedures. The HFEF mode of operations was changed from the MAIN-CELL OPERATING MODE to the MAIN-CELL REPAIR MODE.

The controls for operating the Large Lock Door are located so that the persons operating the controls cannot see the progress/position of the Large Lock Door. The Operator opening the Large Lock Door became distracted while opening the door and did not comply with procedure use and adherence requirements and expectations. In addition, a spotter was not used to ensure the Large Lock Door operations were conducted in a compliant manner.

A failure to follow procedures can lead to significant impacts to facility operations.

\section{Advanced Test Reactor Critical (ATRC) Facility Pre- Startup Testing Anomaly} NE-ID--BEA-ATR-2014-0029 (Significance Category 4) On 10/21/14, at the ATRC reactor, operators were performing reactor pre-startup instrumentation testing. One of the required tests is to verify a reactor SCRAM occurs before $145 \%$ reactor power as indicated on Neutron level Channel "A." When indicated, power reached $141.5 \%$, only one of five safety rods released. The expectation was all five of the rods would insert when the rod release set point was reached. (The ATRC was not in reactor operation at the time of this event, but was in pre-startup testing.)

Operators inserted a manual reactor SCRAM, verified all safety rods fully inserted, terminated pre-startup testing, and the ATRC reactor was verified to be in a safe, shutdown condition. A maintenance work request was submitted to investigate the reactor and make repairs. 


\section{ATR Confinement Door (D-314) Latch Stuck}

NE-ID--BEA-ATR-2014-0031 (Significance Category 4)

On 11/15/14, an ATR Process Operator discovered the latch

for Door 314 (D-314), a confinement door from the north

stairwell and switchgear area in the ATR, was stuck and failed to keep the door latched shut. ATR confinement is required during, and for 30 minutes after, power operations, per ATR TSR-186 LCO-3.8.1., Entry into TSR-186 LCO-3.8.1, for confinement, was not required as the reactor was shut down and defueled and LCO applicability was not met. A work order was submitted to repair the latch.

\section{ATR Reactor Safety System (RSS) Fission Break Channel "B" Failure}

NE-ID--BEA-ATR-2014-0032 (Significance Category 4)

On 11/14/14, ATR Reactor Instrument Control Technicians

(RICT) were performing Detailed Operating Procedure (DOP)-

2.6.52, Reactor Safety System (RSS) Fission Break Subsystem

Response Time Test Channel A, B, and C. During the

performance of channel " $B$," two of the five amplifier ranges exceeded their required response time.

At the time of the fission break channel "B" failure, the ATR was in outage with fuel removed from the reactor vessel.

Consequently, fission break channel " $B$ " was not required to be operable. A work request was initiated to repair the channel.

\section{ATR \#4 Deep Well Pump Failure to Start}

NE-ID--BEA-ATR-2014-0034 (Significance Category 4) On $12 / 8 / 14$, the ATR control room was notified that the \#4 Deep Well Pump (DWP) had not started in automatic as expected to maintain the ground level storage tank inventory above an alarm set point. The Utility Area Operator went to the \#4 DWP controller and found a current imbalance error message on the digital display. ATR TSR-186 LCO-3.2.1.2, Emergency Firewater Injection Supply System, requires DWPs to be operable when the reactor vessel contains irradiated fuel elements. DWP \#1 was selected to be the lead pump to start vice DWP \#4.

At the time of discovery, ATR was shut down and defueled and the emergency firewater injection system to the reactor vessel was not required to be operable. A maintenance work request was submitted to investigate and make repairs to the pump.

\section{ATR Confinement Door (D-314) Latch Stuck} NE-ID--BEA-ATR-2014-0035 (Significance Category 4)

On $12 / 12 / 14$, the ATR SS found that the latch for confinement door (D)-314 was stuck and failed to allow the door to open. The latch would stick and fail to keep the door latched shut as required by ATR TSR-186. ATR Confinement is required during, and for 30 minutes after, Power Operations, per ATR TSR-186 LCO-3.8.1. This same door had recently been repaired and declared operable.

At the time of discovery, ATR was shut down and defueled, confinement was not required to be operable, and LCO applicability was not met. Following discovery, a maintenance work request was issued and repairs on the confinement door were initiated.

\section{Spurious Emergency Flow Channel Alarm at the ATR} NE-ID--BEA-ATR-2014-0037 (Significance Category 4) On $12 / 16 / 14$, the ATR Operations staff was setting up for instrument calibrations that were to occur on day shift. One channel of emergency pump flow Reactor Safety System (RSS) instrumentation began to alarm. The operations staff was unable to get the alarm to reset/clear to support the planned calibrations. Emergency pump flow RSS instrumentation is required to be operable during depressurized operation per ATR TSR-186 LCO-3.1.1(15).

At the time of emergency flow channel failure, the ATR was in outage with fuel removed from the reactor vessel.

Consequently, emergency flow instrument channel was not required to be operable.

A maintenance work request was initiated to troubleshoot and repair the system. The Plant Protective System (PPS) comparator was found to be faulty and has been replaced and tested satisfactorily.

\section{ATR Confinement Doors 18 and $\mathbf{4 2}$ Latch Failures} NE-ID--BEA-ATR-2014-0038 (Significance Category 4) On 12/20/14, the ATR confinement door (D)-43 was found to have a failed latch. ATR Management requested that all confinement doors be checked to identify if other door issues existed due to the length of the current outage and the volume of traffic through the doors.

As a result of this check, another door (D-18) was found to have a damaged seal. The ATR TSR require the doors to shut without interference to ensure they will latch shut with a seal to provide confinement. ATR confinement is required during, and for 30 minutes after, Power Operations, per ATR TSR-186 LCO-3.8.1. At the time of discovery, ATR was shut down and defueled. Confinement was not required to be operable.

Doors and associated hardware are checked during preparations for mode changes where confinement is required. 
ATR Confinement Door 43 (D-43) Bottom Seal Failure NE-ID--BEA-ATR-2015-0002 (Significance Category 4) On 12/28/14, ATR confinement door 43 (D-43) was found to have the bottom seal coming off, preventing the door from properly closing. The seal was removed to allow the door to close. The ATR TSR require confinement doors to shut without interference, and latch shut with a seal to provide confinement. ATR confinement is required during, and for 30 minutes after, Power Operations, per ATR TSR-186 LCO-3.8.1.

Surveillance is performed on confinement doors and associated hardware per a Detailed Operating Procedure (DOP) during preparations for mode changes where confinement is required. A maintenance work request was initiated to repair the failed seal.

At the time of discovery, ATR was shut down and defueled. Confinement was not required to be operable.

\section{Suspect/Counterfeit Bolts Found on Gas Cylinder Cart}

NE-ID--BEA-MFC-201

4-0010 (Significance

Category 4)

On 12/9/2014,

equipment

operators were performing an annual preventative maintenance (PM) load test on a gas cylinder handcart when the bolts for the safety chain mechanism that prevents the cylinders from falling off the cart were identified as potential

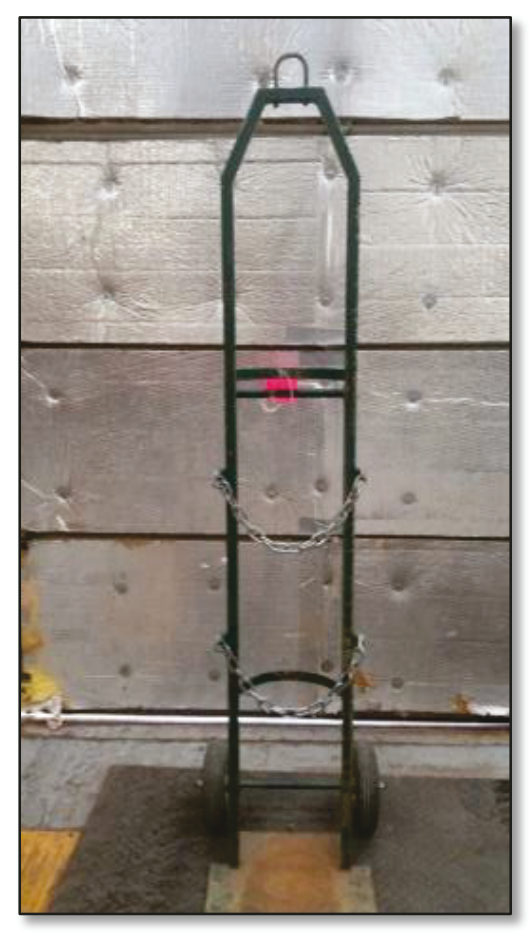

suspect/counterfeit fasteners. The cart has a lifting bail and can be used for rigging gas cylinders out of cells.

MFC Quality Assurance personnel validated that the bolts were listed on the suspect/counterfeit fastener list. The cart was manufactured at MFC in 1990; however, it is unknown when the bolts were installed. The equipment was placed out of service and a maintenance request was issued to replace the bolts.

\section{Suspect/Counterfeit Bolts Found on Coffing Chain Fall} NE-ID--BEA-MFC-2014-0012 (Significance Category 4) On 12/10/14, equipment operators were performing an annual PM load test on a Coffing chain fall when the bolt for the handle was identified as potential suspect/counterfeit fasteners. The following day, MFC Quality Assurance personnel validated that the bolts were listed on the suspect/counterfeit fastener list. The equipment was placed out of service pending replacement of the bolts.

\section{Suspect/Counterfeit Bolts Found on LOED Handler Forklift}

NE-ID--BEA-MFC-2014-0012 (Significance Category 4) On 10/10/14, equipment operators discovered suspect fasteners on a LOED Handler forklift. The following day, MFC Quality Assurance validated that the bolts were listed on the suspect/counterfeit fastener list.

In each of these three events, MFC's efforts to identify suspect/counterfeit bolts are commendable and remind us that both new and old equipment may contain suspect/counterfeit parts. Never let your guard down and always be diligently looking for suspect/counterfeit parts.

\section{Other Non Reportable Events}

There were no additional non-reportable events related to facility status reported during the $1^{\text {st }} \mathrm{Qtr} F Y-15$. 


\section{TREND SNAPSHOT}

Environmental Events: Similar to last quarter, there was one environmental event reported in the $1^{\text {st }} Q \operatorname{tr} F Y-15$. The rate of occurrence of environmental events is beginning to stabilize; however, is trending very slightly upwards due to new 40 CFR, Part 63, Subpart ZZZZ (also known as Quad Z) requirements. Although the event reported this quarter is exact in nature to the environmental event reported the past three quarters, its occurrence is not indicative of an averse trend, but is the result of changes to 40 CFR Part 63.

When compared to the balance of the DOE complex, the percentage of occurrence of Group 5 environmental events at INL is slightly higher than that of the balance of the DOE Complex (4\% to $3 \%$ ) and is stable with that reported in FY-13. All four of the environmental events reported in the last year are related to 40 CFR Part 63, Subpart ZZZZ requirement changes.

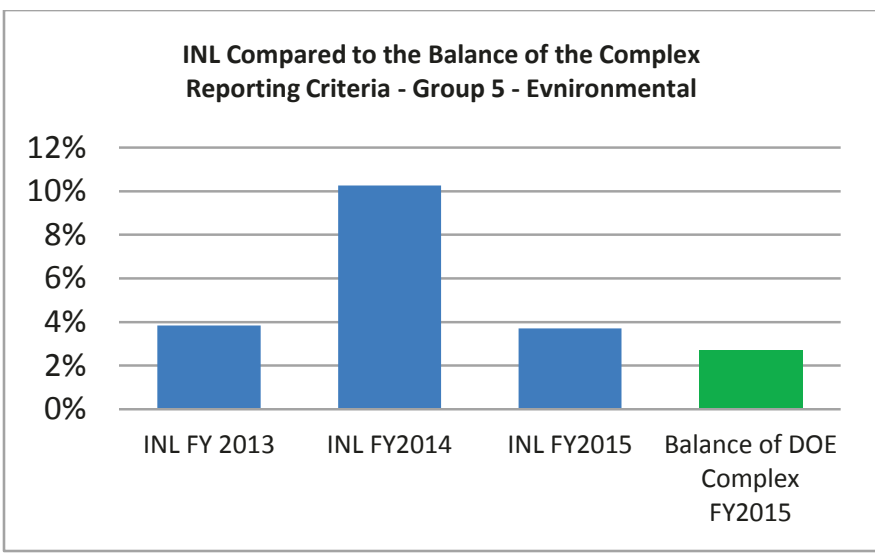

Events related to environmental problems are one of the least reported event types, accounting for only four events in the past 12 months, one of which was reported in the $1^{\text {st }}$ Qtr FY-15. This event is described in the following paragraph.

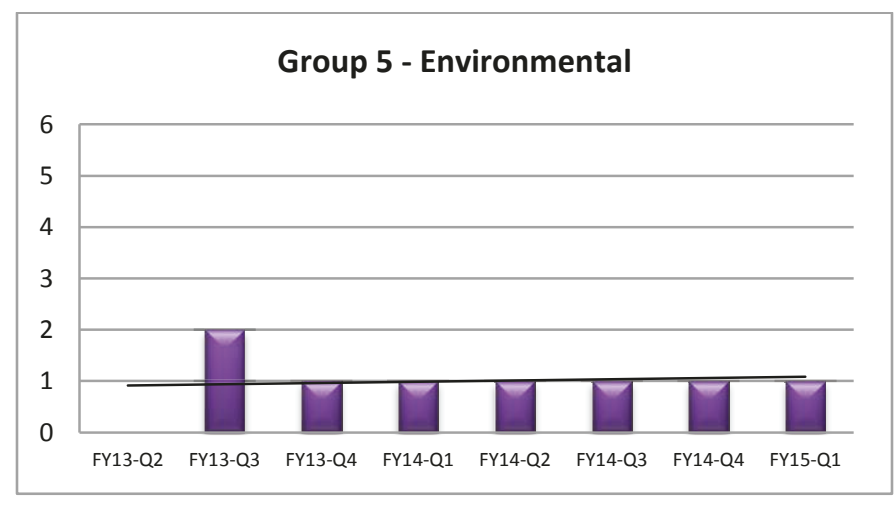

\section{Quarterly Report of Diesel Engine Startup at the Advanced Test Reactor (ATR)}

NE-ID--BEA-ATR-2014-0002 (Significance Category 4)

New environmental regulations, operation, and maintenance requirements for ATR Complex diesel engines are in effect: 40 CFR, part 63, subpart ZZZZ, National Emissions Standards for Hazardous Air Pollutants for stationary reciprocating Internal Combustion Engines (RICE), also known as Quad Z.

The following ATR Complex engines are non-emergency stationary RICE: Generators 670-M-42, 670-M-43, and 674-M6. Without installation of emissions controls, units $670-\mathrm{M}-42$, 670-M-43, and 674-M-6 do not meet the new emission standards for hazardous air pollutants that went into effect on May 2, 2013. INL has negotiated with the Idaho Department of Environmental Quality (DEQ) a Voluntary Consent Order (VCO) to replace units 670-M-42 and 670-M43 with a commercial power based uninterruptible power supply (UPS). When the UPS project is complete in 2015, all three units will be designated as emergency stationary RICE.

\section{Other Non Reportable Events}

There were no additional non-reportable events related to environmental problems reported during the $1^{\text {st }}$ Qtr FY-15. 


\section{TREND SNAPSHOT}

Contamination/Radiation Events: There were no reportable events related to contamination/radiation control reported in the $1^{\text {st }} Q \operatorname{tr} F Y-15$. The ATR facility has recently reported almost 62,000 radiological entries and 336,000 radiological work hours without a single skin or clothign contamination event. The rate of occurrence of these types of events is trending downwards over the past two years. During the last twelve months, only one reportable event (personnel skin contamination) at the MFC Analytical Laboratory, was documented in ORPS. There were two non-reportable events documented this quarter. They are summarized below.

When compared to the balance of the DOE complex, $0 \%$ of the events reported at INL were reported under Group 6 Contamination/Radiation criteria; the balance of the DOE complex reported $6 \%$ of events under the same criteria. INL events reported in FY-12, included discovery of radioactive particles at ATR, and several events at MFC, including the plutonium contamination event in the Zero Power Physics Reactor (ZPPR). Since these events, added rigor to radiological work has paid off and is seen as a reduction in the number of radiological events.

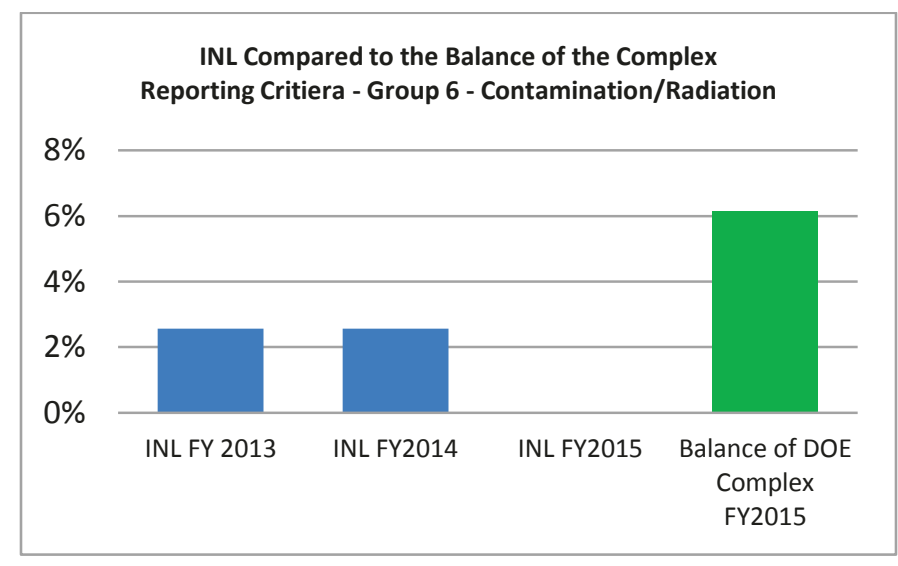

Events related to contamination and/or radiation control are some of the least reported event types at INL; these events have only accounted for one reportable event in the past 12 months. There were no reportable contamination/ radiation control events that occurred in the $4^{\text {th }}$ Qtr FY-14.
Group 6 - Contamination/Radiological Controls

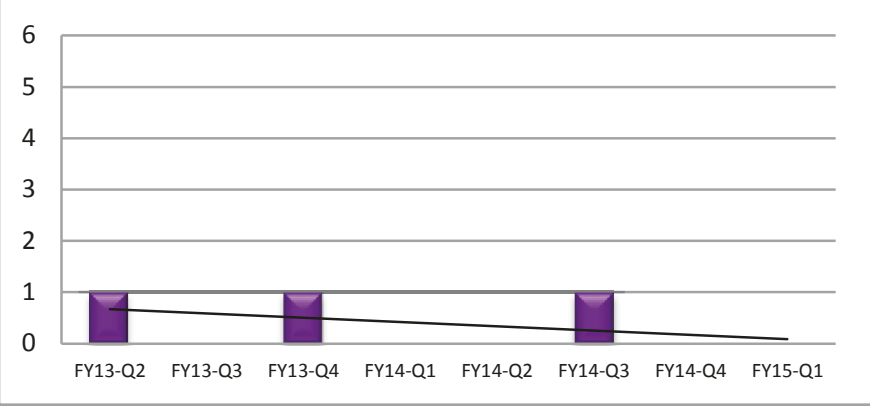

\section{Other Non-Reportable Events}

CO-2014-4671

Sometime between $9 / 25 / 14$ and $10 / 1 / 14$, a scaler used in the Analytical Lab (AL) and Radiochemistry Lab (RCL) was shipped from MFC to the Health Physics Instrument Lab (HPIL) for calibration. Upon arrival at CFA, a Radiological Technician identified higher than background counts on the face of the scaler. The RCL supervisor was notified and additional surveys were taken.

After disassembly of components on the scaler, additional contamination was identified on the locking mechanism that pushes the slide into place for the scaler to initiate the counting process. A sample was taken and sent to the AL for analysis. It was determined that the contamination was cesium and radon daughter products, which were not used in $\mathrm{RCL}$ or in the $\mathrm{AL}$.

During an investigation into the event, INL learned that the procedure for releasing materials was not followed when the equipment was removed from a Radiological Buffer Area. In addition, the process for picking up instruments such as the scaler is not defined. 


\section{Other Non-Reportable Events}

CO-2014-5415

On $11 / 3 / 14$, a management observation of the shipment of the ATR Resin Cask was performed. The cask was loaded with the resin liner, sitting on the trailer with the trailer attached to an INL tractor truck inside TRA-617. While Waste Generator Services (WGS) personnel were assembling for the Pre-Job Brief, the Equipment Operators and Radiological Controls Technicians (RCT) moved the cask out from the TRA617 Pad and unhooked the tractor from the trailer with the cask, leaving the trailer it staged on the pavement next to the pad.

The RCTs then informed those assembled for the pre-job brief that no personnel were authorized within two meters of the cask without dosimetry. At this time, not all parties had arrived and the Waste Technical Specialist was unable to begin the pre-job briefing.

Several minutes later, Packaging and Transportation (P\&T) personnel and the truck driver arrived. WGS then began gathering personnel for the briefing. As personnel were assembling for the pre-job, an individual was observed approaching the cask in an attempt to remove old labeling. The Waste Technical Specialist asked the individual to stop and attend the briefing before starting work.

During the brief, the RCT stated that work on the cask required being on the Radiological Work Permit (RWP). Following the briefing, all personnel that needed to work in the two meter zone of the cask signed onto the RWP and performed their work.
Follow up discussion with P\&T and Radiological Controls Supervisors regarding the individual being inside the two meter perimeter without being on the RWP resulted in the discovery of a procedural violation of MCP-187, "Posting Radiological Control Areas."

This event shows us that it is imperative to properly post areas (both radiological and non-radiological), to ensure that all necessary personnel are in attendance for pre-job briefings, and to not begin work until authorized to do so.

\section{Update on MFC-704 FMF Suspect Contamination Found on CAM Filters}

NE-ID--BEA-FMF-2014-0001

The INL ONA was tasked to perform an independent assessment of the events leading up to discovery of contamination on Continuous Air Monitor (CAM) filters in the Fuel Manufacturing Facility (FMF). While ONA was unable to identify a direct cause of the airborne release, they were able to identify several performance deficiencies, areas of improvement, and recommendations. These are being considered by MFC management.

To identify the source of the contamination, a structured test program developed by MFC FMF Advanced Fuel Cycle Initiate operations personnel is underway. This program will attempt to reproduce the airborne event and is scheduled to be completed in late February 2015. A status of the results of the test will be provided next quarter.

\section{$1^{\text {st }}$ Qtr FY-15 GROUP 7 - NUCLEAR EXPLOSIVE SAFETY EVENTS}

There were no events related to nuclear explosive safety during the $1^{\text {st }}$ quarter FY-15. BEA has never reported an event under this reporting criterion since taking over the contract for the INL in 2005. Of the 241 events reported across the DOE Complex during the $1^{\text {st }}$ quarter of FY-15, none were reported under the Group 7 - Nuclear Explosive Safety Events criterion. 


\section{TREND SNAPSHOT}

Packaging/Transportation Events: There were no packaging and transportation events reported during the $1^{\text {st }} Q \operatorname{tr}$ FY-15. The two year trend data for these types of events shows a decreasing trend. Over the past 12 months, there have been no P\&T-related reportable events documended in ORPS.

INL rarely reports events under Group 8 Packaging and Transportation criteria. As compared to the balance of the DOE Complex, $2 \%$ of all reportable events documented in ORPS during the $1^{\text {st }}$ Qtr FY-15 were related to P\&T.
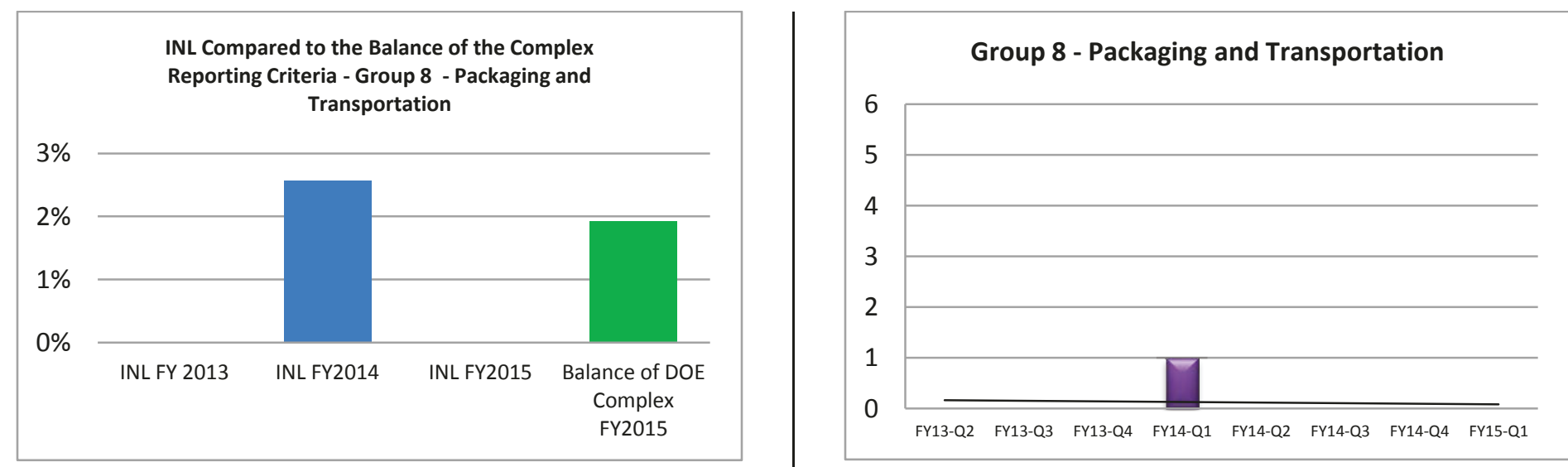

Events related to packaging and transportation rarely occur at INL; there has been one such event in the last two years.

\section{$1^{\text {st }}$ Qtr FY-15 GROUP 9 - NONCOMPLIANCE NOTIFICATIONS EVENTS}

\section{TREND SNAPSHOT}

Packaging/Transportation Events: Noncompliance notification events are reported when the INL receives written notification from an outside regulatory agency that the site or an INL facility is considered to be in noncompliance with a schedule or requirement. Over the past 12 months, the INL has been issued two noncompliance notifications and has reported them through ORPS. Both of these were reported during the $4^{\text {th }} \mathrm{Qtr} F Y$-14. There were no events reported under this criteria during the $1^{\text {st }}$ Qtr FY-15. The two year trend data for these types of events shows a slight increase trend because of the events reported last quarter. 
The balance of the DOE Complex reported approximately $3 \%$ of events under this reporting criterion.

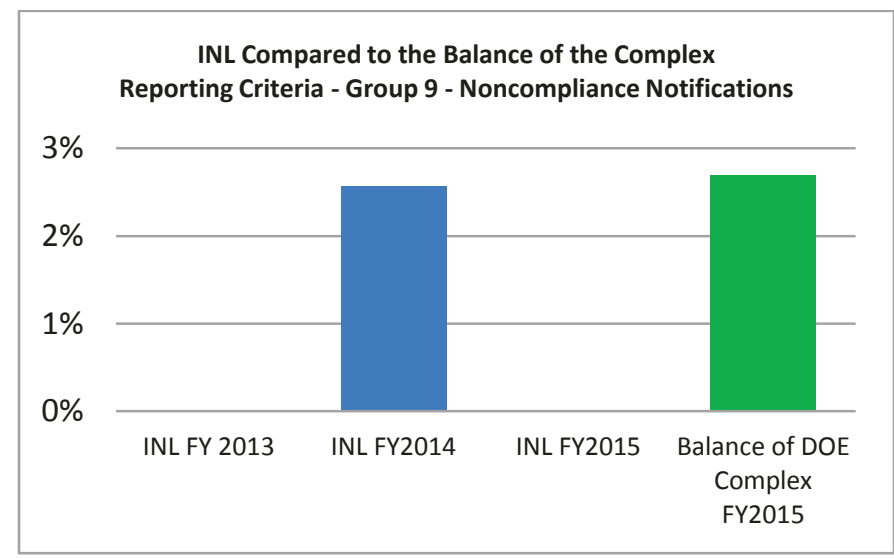

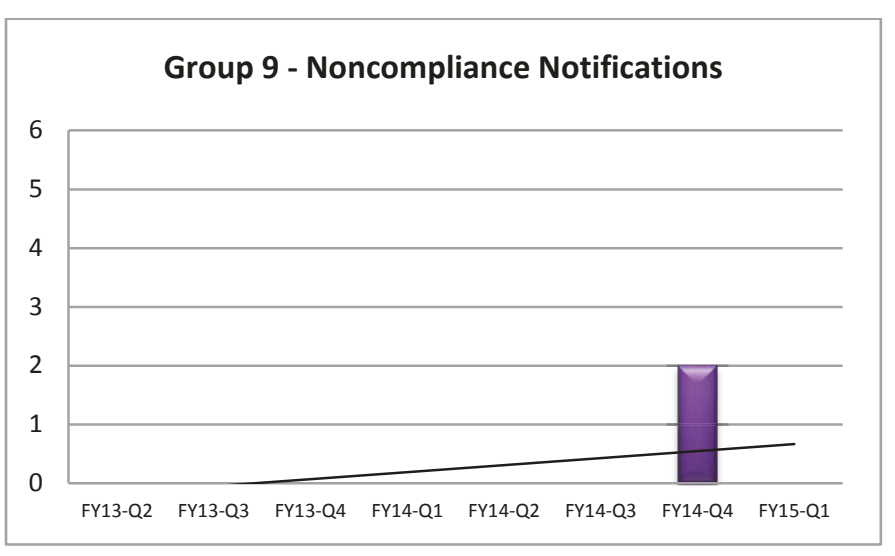

\section{Other Non Reportable Events}

There were no additional non-reportable events related to noncompliance notifications reported during the $1^{\text {st }}$ Qtr FY-15.

\section{$1^{\text {st }}$ Qtr FY-15 GROUP 10 - MANAGEMENT CONCERNS AND ISSUES}

\section{TREND SNAPSHOT}

Management Concerns and Issues: Four events were reported during the $1^{\text {st }}$ Qtr FY-15 under reporting critiera for a management concern or issue. Two of these were reported as near misses, the other two as events or conditions that did not meet reporting criteria, but were determined by the Facility Manager or line management to be of safety significance or of concern for that facility or other facilities or activities in the DOE complex.

The number of management concerns increased from three last quarter to four this quarter. The rate of occurrence is trending slightly downward over the past 12 months. During the past 12 months, INL reported nine events under Group 10 management concerns.

The balance of the DOE complex reported $33 \%$ of all events in the $1^{\text {st }}$ Qtr FY-15 under Group 10 Management Concern criteria. In comparison, only $15 \%$ of INL events were reported under this criteria.

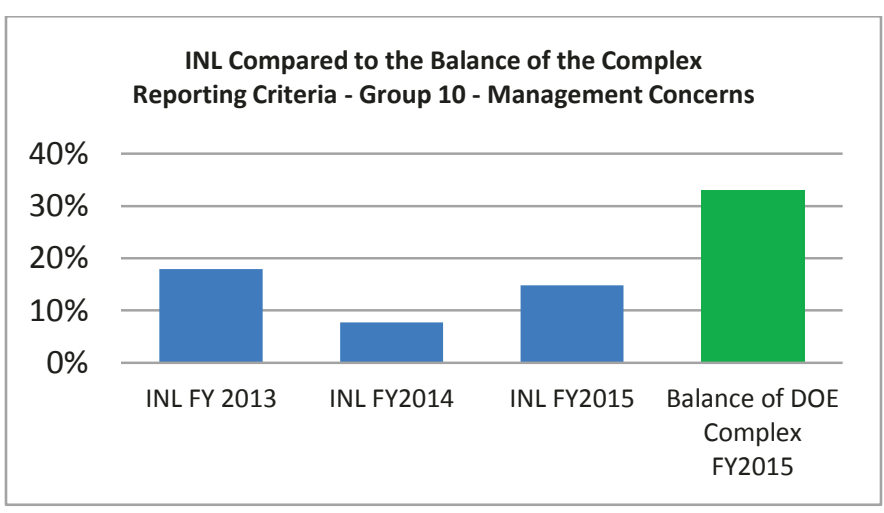




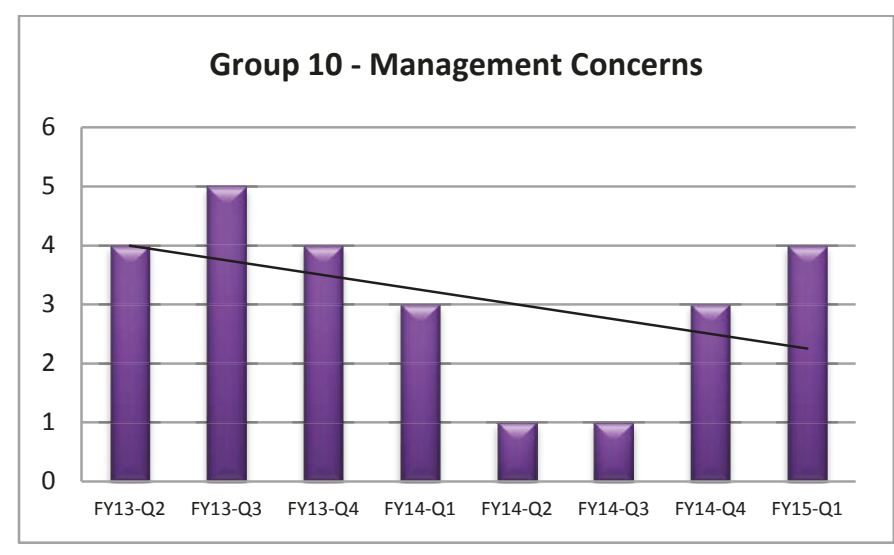

The four events reported during the $1^{\text {st }}$ Qtr FY-15 are summarized below.

\section{Lockout Tagout Inadequacies}

NE-ID--BEA-MFC-2014-0005 (Significance Category 4) A PM evolution on a motorized damper (BEX-MD-002) for the Irradiated Materials Characterization Laboratory (IMCL) Suspect Exhaust ventilation was approved for work. The SS made a decision to re-use a Simple LOTO permit that had been used a few weeks prior on a maintenance evolution on the related exhaust fan (BEX-EF-002). The LOTO isolated a 480VAC supply line.

After the work was completed, the SS was investigating a ventilation issue (later found to be unrelated) and learned that the mechanic worked on the wrong damper (BEX-DMP002), which was the manual damper downstream of BEX-EF002. Additional errors were identified on the LO/TO; however, it was determined that hazardous energy was not present for either damper.

\section{Conduit Damaged During Core Drilling Activities}

NE-ID--BEA-HFEF-2014-0004 (Significance Category 3) On $10 / 13 / 14$, a subcontractor penetrated a conduit while core drilling through the HFEF Control Room wall from the Operating Corridor. The damage to the conduit exposed two electrical conductors, but did not damage the conductor insulation. The conduit contained two energized $120 \mathrm{~V}$ lines supplying power to the HFEF Control Room lights.

Subcontractor was using a grounded $120 \mathrm{~V}$ core drill plugged into a Ground Fault Current Interrupter (GFCI) receptacle.

The investigation into the event revealed that a subsurface investigation was not performed in the area where core drilling took place due to space constraints/collocated conduit. A penetration permit had not been written specifically for work being performed. The permit in the work package was for the work performed previously; this work had been added to the subcontract. Work approval was assumed based on subcontract extension/addition of work to the contract.

Subcontract workers did not walk-down the job with a CFR and instead assumed location was approved for core drilling. Finally, BEA requirements listed in RD-2014, "Excavation and Surface Penetrations" were not included in the Job Safety Analysis being used. The use of a "shunt trip" for a grounded/not double-insulated/drill as listed in RD-2014, was not included in Job Safety Analysis.

What can we learn from this event? During reviews of subcontractor Work Control Documents, ensure applicable requirements from laboratory-approved requirements documents are included. A shunt device is required when using grounded electric handheld tools (i.e., drills, saws, etc.) when cutting or drilling into concrete.

\section{CFA-623 Malfunction of Equipment}

NE-ID--BEA-CFA-2014-0004 (Significance Category 3)

Subcontractor and BEA personnel were programming/testing newly installed electrical upgrade equipment in CFA-623/624 when a relay switch malfunctioned and short circuited the $480 \mathrm{~V}$ relays. This caused a 5 " $\times 8$ " $\times 3$ " lid to become displaced from the box. Personnel in the vicinity were wearing the required Personal Protective Equipment (PPE) and no injuries occurred as a result of the event.

Following the event, all testing/programming was stopped and the subcontractor initiated a stop work. The equipment failure was placed in a safe configuration and an investigation into the failure was initiated.

\section{Stop Sign Pole Snaps While Being Straightened}

NE-ID--BEA-MFC-2014-0006 (Significance Category 3)

On 11/4/2014, maintenance work was being performed on a bent stop sign pole located in the MFC parking lot. The pole was bent several years prior when a vendor struck the pole.

The work instructions required that the pole be straightened or replaced. Initially, during a pre-job briefing, the craftsmen and foreman discussed using a porta-power jack to straighten the pole. After evaluating the situation, the craftsmen and foreman determined a better way to straighten the pole was to wrap a strap around the pole and use a chain fall, anchored to the bumper of a truck to pull the pole back into place. This decision was based on the fact that the pole was bent and trying to slide the bent pole off the bent sleeve in order to straighten the pole could not be easily performed. 
Once the work commenced, three attempts were made to straighten the pole, each time revealed some progress in straightening the pole, but the pole could not be completely straightened. During the 4th pull, the stop sign's inner pole sheared at the base, fell, and dented the tailgate of a government vehicle.

One of the craftsmen was standing to the side of the pole when it sheared and was uninjured during the event. The craftsmen stopped work and immediately notified their foreman.

An investigation into the event showed that the maintenance crew had assumed that the installation was similar to others they had encountered. When the sign post did not straighten after three attempts, a fourth attempt resulted in the aluminum pipe breaking. A step-back to investigate after the first three attempts may have prevented the event. In addition, the hazard mitigation was not comprehensive enough to protect workers and equipment.

Some lessons we can learn from this event include: Never assume that all situations present the same conditions; step back and investigate when things are not going as planned; be aware of the potential of stored energy and use appropriate barriers to protect people and equipment.

\section{Other Non-Reportable Events}

There were no additional non-reportable conditions that are being addressed as management concerns.

\section{$1^{\text {st }}$ Qtr FY-15 EVENTS INVOLVING SUBCONTRACTORS}

\section{TREND SNAPSHOT}

Events Involving Subcontractors: Three events involving subcontract employees occurred during the $1^{\text {st }}$ Qtr FY-15. The number of reportable occurrences involving subcontractors continues to trend downwards over a two year period. There are no noted trends (e.g., causes, subcontractor involved, etc.) associated with events involving subconract personnel.
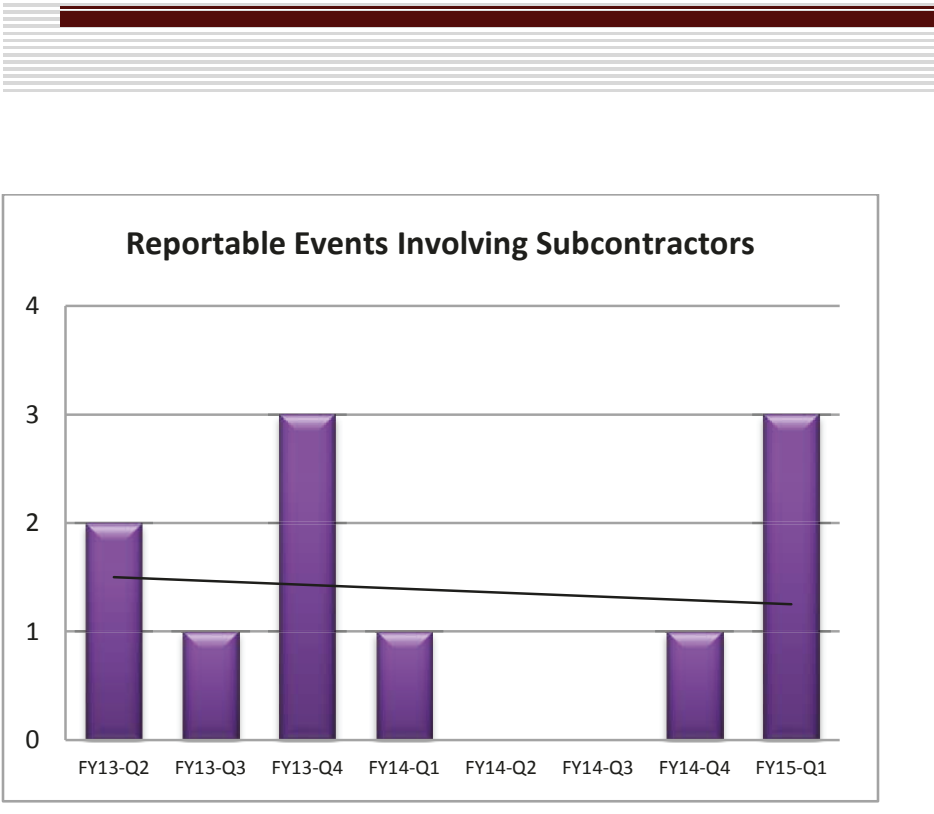

There have been 11 ORPS reportable events involving subcontractors during the past two years; three were reported during the $1^{\text {st }} \mathrm{Qtr} F Y-15$. These include the damaged conduit event reported under NE-ID--BEA-HFEF-2014-0004, the CFA-623 malfunctioning equipment reported under NEID--BEA-CFA-2014-0004, and the event where a LOTO was not followed when connecting electrical power to a trailer reported under NE-ID--BEA-CFA-2014-0005. 
Cause codes documented in ORPS were analyzed through ORPS distribution trend reports to get an understanding of what is causing or contributing to events at INL. The data was reviewed to determine causes over the past year and two years. The analysis shows that the majority of causes over both time periods can be attributed to management, human performance, and communications.

The percentages of events caused in part by management, by less-than-adequate human performance, and by less-thanadequate communications are dropping when compared to the percentage reported two years ago. This decline is indicative of successful mentoring and oversight achieved by having management spend time in the field, watching work and addressing incorrect behaviors before they lead to events. INL expects more improvement in these areas as the new management observation program (ObservationWay) is rolled out across the INL.

Analysis of reportable events has identified an increase in problems associated with design and engineering (A1 cause codes), as well as an increase in equipment and material problems ( $A 2$ cause codes). Many of the equipment problems were discovered during turnaround activities at the ATR. ATR is aware of the problem and is seeking increased funding to address known equipment deficiencies.

The chart below shows the trending of reportable events by cause code.

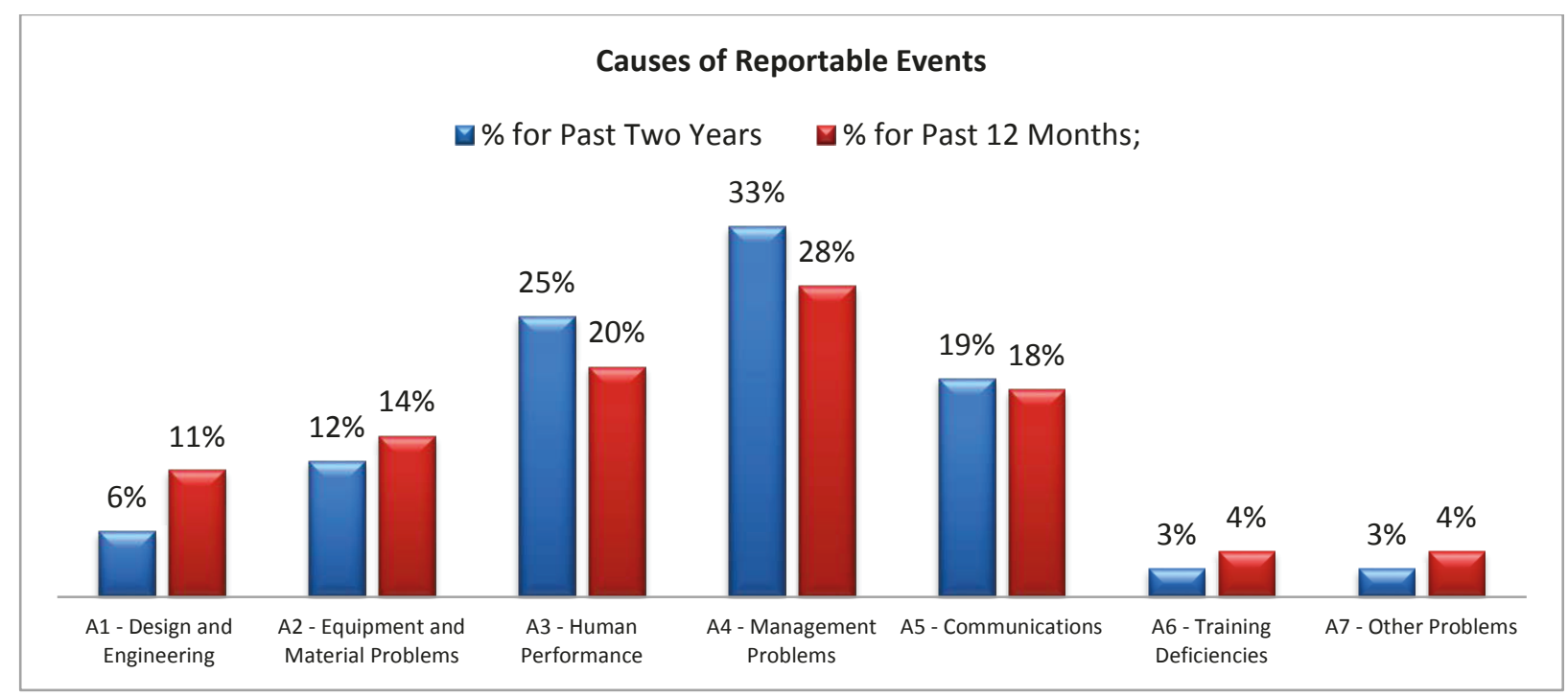

In addition to evaluating the cause of events, INL analyzes each reportable event to identify where we failed to effectively implement the five Integrated Safety Management System (ISMS) core functions. The chart below shows Significance Category OE, R, 1, 2, and 3 events that occurred at INL and their corresponding ISMS core function failures.

For the majority of events (66\%), the ISMS Core Function analysis indicated that there were no known failures of the ISMS process. This is true for equipment problems and discovery of suspect counterfeit parts. Twenty percent of the events indicated execution of Core Function 4 - Perform Work within Controls was problematic. To address this, INL included procedure compliance as a key topic in continuing Conduct of Operations training held throughout FY-14. In addition, enhanced oversight of work activities through management observation will help ensure personnel are performing work in accordance with procedures.

\section{ISMS Core Function Failures Last 12 Months}

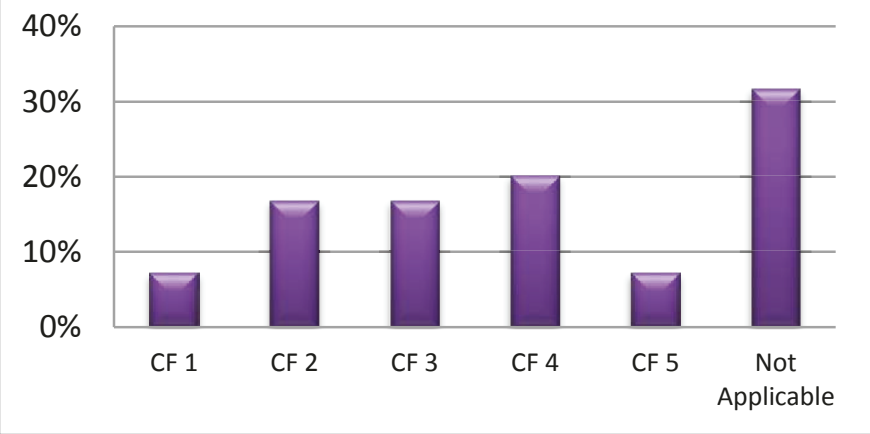


The INL management observation program enables safe, secure, efficient, and effective work performance through regular, purposeful, and documented management presence where and when employees perform work. This is achieved by management personally observing work activities and communicating with employees to solicit input and provide mentoring, coaching, and timely feedback on behaviors. This program strengthens application of Core Function 4 by ensuring personnel are performing work in accordance to procedures and work control documents.

\section{$1^{\text {st }}$ Qtr FY-15 ANALYSIS OF IOPAC TRENDING ANALYSIS}

\section{TREND SNAPSHOT}

Integrated Operations Performance Analysis Committee (OPAC) Trending Analysis: For the $1^{\mathrm{ST}}$ Qtr FY-15, the eight mission centers [ATR, MFC, SMC, National and Homeland Security (N\&HS), Nuclear Science and Technology (NS\&T), Energy and Environment Science and Technology (EES\&T), Facilities and Site Services (F\&SS), and Laboratory Protection (LP)] continued to evaluate ORPS events, INRs, and LabWay issues for trending. In addition, analysis from the Radiological Controls Management System, the INL Work Management System, and Conduct of Operations were also presented by the IOPAC to INL Senior Management. Issues common across the INL and issues that continue to affect the INL are summarized below.

The IOPAC meets monthly to discuss actions being taken at the Laboratory Mission Centers and share lessons across the centers. The IOPAC team has been working on actions to address the following:

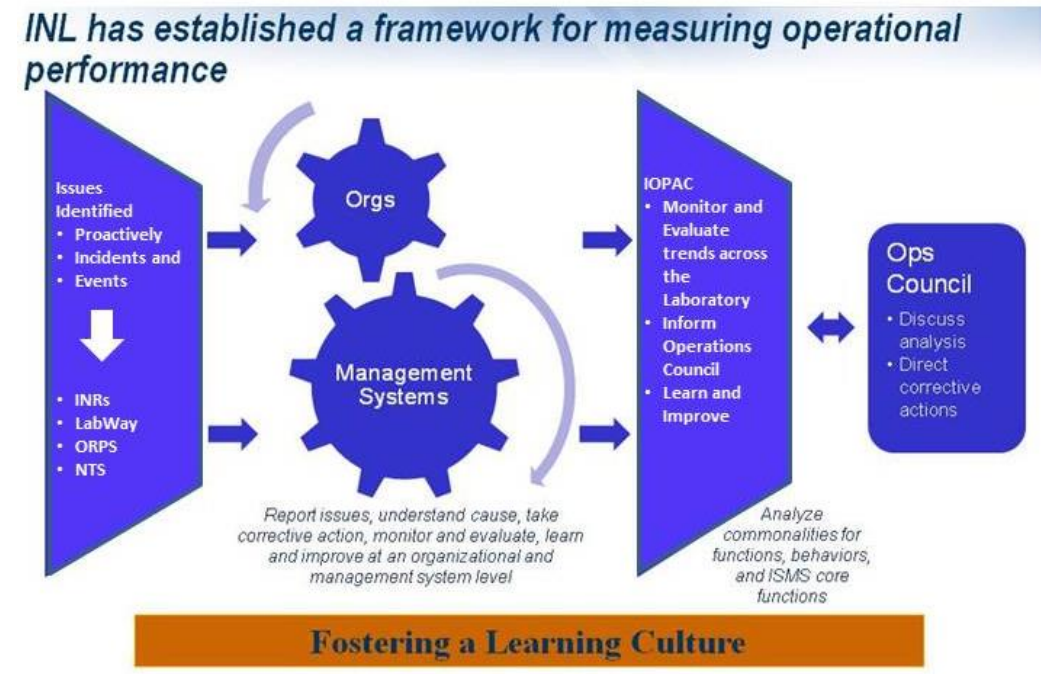

Figure 1. Framework for Measuring Operational Performance
- The initiative to improve coding of conditions in LabWay resulted in a revision to the discipline codes. The codes now better align with laboratory processes and programs.

- Initiatives to improve implementation of conduct of operations principles are being noted across the laboratory. Conduct of Operations core training has been revised and has received positive feedback.

- Increasing management field presence throughout the laboratory through a structured Management Observation Program and mentoring.

- Management of legacy issues (those older than 200 days) continues. Both the average age of open conditions and total population of open conditions continue to increase. Approximately $20 \%$ of the total population has been flagged as long-term. These conditions are being assessed to determine if they meet established guidelines. 


\section{INL Quality and Performance Management Expectations}

The INL mission involves performing and deploying world class research that meets the nation's needs in the areas of nuclear energy, other energy, the environment, and national security. Quality and Performance Management plays a critical role in supporting the INL mission. Our mission is to:

- Ensure we as a Lab know how we are doing and are improving our performance.

- Own and manage the Laboratory Issues Management System.

- Provide high quality QA program support for research and operations.

- Provide effective independent oversight.

"In order to be successful, we must be leaders, we must be competent, and we must be accountable. We must also exhibit the INL values of excellence, integrity, ownership, and teamwork."

- Chris Hott, Director-INL Quality and Performance Management

Idaho National Laboratory INL Quality and Performance Management P. O. Box 1625, Mail Stop 3206

Idaho Falls, ID 83415

\section{INL/EXT-15-34291}

